\title{
LO QUE "OCULTA" EL ESTILO: MATERIAS PRIMAS Y MODOS DE HACER EN LA ALFARERÍA BELÉN. APORTES DESDE LA PETROGRAFÍA DE CONJUNTOS CERÁMICOS DEL VALLE DEL BOLSÓN (BELÉN, CATAMARCA, ARgENTINA)
}

\author{
Verónica Puente
}

\section{* Introducción}

Este trabajo contribuye al estudio de las prácticas de producción alfarera que se desarrollaron durante el lapso comprendido entre ca. 900-1600 DC en el área valliserrana del Noroeste Argentino, a partir del análisis tecnológico de conjuntos cerámicos identificados bajo la unidad estilística Belén. El tema se aborda a través de estudios petrográficos de una muestra numerosa procedente del valle del Bolsón

(Catamarca, Argentina). Los resultados alcanzados permitieron identificar la coexistencia de elecciones compartidas y otras diferenciadas entre los alfareros que elaboraron estas piezas. Se destaca gran homogeneidad en las materias primas utilizadas, las cuales a su vez coinciden con las identificadas en la región, pero se reconoce diversidad en otros aspectos de la elaboración de las piezas, resultados que se interpretan como consecuencia de una producción de pequeña escala y baja intensidad.

Palabras claves: estilo Belén - modos de hacer - materias primas.

Abstract

This paper contributes to the knowledge of ceramic production in the Valliserrana area (Northwest Argentina) during the AD 900-1600 period through the technological analysis of ceramic assemblages of the Belen stylistic unit. The subject is approached on the basis of petrographic studies of a large sample of fragments from the Bolson Valley (Catamarca, Argentina). The results indicate that some technological choices were shared by the potters who made the vessels, but others were not. There is a remarkable homogeneity in the raw materials, which correspond to those characterized in the region, but there is considerable diversity in other aspects of their manufacture. These trends are interpreted as a result of small scale, low intensity production.

Key words: Belén style - ways of production - raw materials. Recibido: julio 2011. Aceptado: diciembre 2011.

La alfarería identificada como Belén fue recuperada en diversos sitios del área valliserrana del Noroeste Argentino (NOA) y se encuentra vinculada a ocupaciones del tardío prehispánico (ca. 900-1600 DC). Este estilo cerámico se originó como una categoría museográfica en los primeros años del siglo XX y fue resignificado como reflejo de una estructura política (señorío), un período (Tardío o Desarrollos Regionales), una entidad étnica (los Diaguitas) y cultural (Belén) particular, aspectos que desde hace unos años son discutidos críticamente (Quiroga 2003). Las características morfológicas, iconográficas y de color fueron los elementos a partir de los cuales se definió esta unidad estilística y son los atributos diagnósticos utilizados para clasificar como tal a piezas enteras y fragmentos cerámicos, a pesar de la diversidad reconocida entre distintos ejemplares en los tipos de contornos, tratamientos de superficies, morfología de las asas, terminación de las piezas, etc. En este sentido, el estilo Belén es una categoría construida y utilizada por los investigadores a partir de caracteres percibidos como constantes dentro de un universo cerámico que integra su propia variabilidad. Más allá de dicha constancia en la apariencia externa o estructura general que poseen estos ejemplares, se encuentran "ocultos" a nuestros ojos un conjunto de rasgos que nos permiten inferir distintas elecciones que los alfareros tomaron durante algunas etapas del proceso de elaboración de las piezas, entre ellas la selección y el tratamiento de las materias primas, la conformación de la pasta y algunas técnicas de modelado y cocción. Este es el propósito del presente trabajo: contribuir en el estudio

1 CONICET. Universidad Nacional de Mar del Plata, Facultad de Humanidades, Laboratorio de Arqueología. Peña 4046, $1^{\circ}$ piso. ARGENTINA. Email:vpuente78@yahoo.com.ar 
de las materias primas y de los modos de elaboración de las pastas de la alfarería que identificamos como Belén y, de este modo, analizar "lo que oculta el estilo", es decir, parte de las elecciones involucradas en las prácticas de producción de las piezas y que no fueron contempladas en la definición de esta unidad estilística.

Específicamente, se aborda el análisis tecnológico a través de la petrografía cerámica de un conjunto numeroso de piezas procedentes de los sitios La Angostura, El Duraznito y Los Viscos, asentamientos ubicados en el valle del Bolsón (Depto. de Belén, Pcia. de Catamarca, Argentina). Asimismo, los resultados alcanzados constituyen un importante aporte desde una base empírica específica, para debatir el tema de la organización de la producción cerámica durante el tardío prehispánico en el NOA.

Desde las primeras descripciones de este tipo de piezas realizadas en los últimos años del siglo XIX hasta la actualidad, las características morfológicas e iconográficas observadas fueron las variables que recibieron mayor interés de ser estudiadas y a través de ellas se abordaron y discutieron problemas cronológicos, identitarios y de interacción regional desde posturas teóricas y analíticas diversas (Lafone Quevedo 1892; Outes 1907; Bruch 1911; Bregante 1926; Bennet et al. 1948; González 1955; Cigliano 1958; Serrano 1966; Sempé 1977; Basile 2005, 2009; Wynveldt 2006, 2007, 2009; Puente y Quiroga 2007a, 2007b; Quiroga y Puente 2007a, 2007b Ms; Wynveldt y Iucci 2009). Recientemente, el estudio de estas piezas se ha enfocado hacia aspectos tecnológicos a partir de análisis petrográficos, mineralógicos y químicos de las pastas y de marcas y técnicas de elaboración de conjuntos procedentes de distintas regiones, entre ellas del valle del Bolsón, valle de Tafí, valle de Hualfín, valle de Abaucán y del Bolsón de Fiambalá, que permiten abordar desde ópticas diferentes el tema de las prácticas de producción de este conjunto (Wynveldt et al. 2005-07; De la Fuente 2007; Páez et al. 2007; Puente 2008 Ms, 2010a; 2010b; 2011a, 2011b; Wynveldt 2008; Feely 2010; Zagorodny et al. 2010).

En este trabajo, el interés de analizar los modos de elaboración de las pastas y las materias primas de piezas incluidas dentro de esta unidad estilística reside en responder a los siguientes interrogantes: iestos objetos que a partir de sus características formales e iconográficas generales percibimos como semejantes $y$, por lo tanto, agrupamos bajo un mismo estilo cerámico, fueron elaborados con modos de hacer homogéneos y estandarizados o es posible identificar diferencias significativas en sus formas de elaboración?, y a partir de ello, ¿cómo se relacionan dichos modos de hacer con la escala y las características de la organización de la producción alfarera?

En un trabajo previo, estos interrogantes fueron abordados con una muestra más pequeña, correspondiente específicamente al sitio La Angostura y desde un acercamiento que integró el análisis de pastas por lupa binocular y de marcas de elaboración identificadas en las superficies de los fragmentos y otras expuestas a partir de la ruptura de las piezas (Puente 2011a). Los resultados obtenidos en esa instancia de investigación permitieron detectar diversidad de modos de elaboración de las pastas y también en las técnicas de construcción de piezas de forma y de tamaño similar. A partir de ello, se planteó que en la producción de las piezas de estilo Belén los alfareros jerarquizaron las características externas generales de la alfarería por sobre los estilos tecnológicos de elaboración, es decir, el interés de los artesanos fue elaborar piezas semejantes en su estructura morfológica, de diseño y color más allá que los modos de elaboración utilizados para dicho fin hayan sido diversos. En este trabajo se profundizan dichos resultados con una muestra más numerosa y a partir de la información obtenida con una herramienta analítica de mayor alcance y precisión como es el estudio petrográfico de las pastas con microscopio de luz polarizada. Esta herramienta es adecuada para indagar sobre los modos de hacer las piezas como también sobre las materias primas, específicamente las inclusiones no plásticas, con las que fueron elaboradas (Middleton y Freestone 1991; Cremonte 1996, 2004; Drucy Gwyn 1998; Stoltman 2001, entre otros). De este modo, este acercamiento permite por un lado, discutir sobre las elecciones que realizaron los alfareros en algunas etapas del proceso de elaboración -selección y tratamiento de las materias primas, preparación de la pasta y cocción- y, por otro lado, abordar una primera etapa en los estudios de procedencia. En relación a esto último, se realiza un análisis petrológico en el cual se compara la petrografía cerámica con la de sedimentos muestreados en distintos sectores del valle.

En síntesis, ambos aspectos de la alfarería, lo que metafóricamente denomino "visible" y "oculto", representan 
procesos de creación de significados dado que con ellos y a través de ellos se crean, reproducen y transforman relaciones y representaciones sociales diversas. A partir de los resultados aquí alcanzados, desde un conjunto cerámico específico y procedente de un valle en particular, se intenta generar un aporte significativo en el estudio de las prácticas de producción alfarera desarrolladas durante tiempos prehispánicos tardíos en el área valliserrana del NOA.

\section{* Prácticas de producción alfarera y modos DE ELABORACIÓN: ACERCAMIENTO TEÓRICO-METODOLÓGICO}

Entiendo a las prácticas de producción alfarera en términos de procesos sociales de elaboración, resultado de un conjunto de elecciones que los artesanos realizan -algunas conscientes y otras naturalizadas y reproducidas de manera inconsciente- en las que se entretejen consideraciones materiales, sociales y simbólicas. En ese sentido, el proceso de manufactura es asimismo una instancia de construcción y reproducción social (Lemonnier 1992; Mahias 2002; Van der Leeuw 2002). Este acercamiento es acorde a la perspectiva de la Antropología de la Tecnología, la cual considera a la tecnología como un fenómeno social en sí mismo y jerarquiza el estudio de las elecciones particulares que rigen una producción, el contexto social en el cual se realizan y la manera en que influyen en las transformaciones sociales (Lemonnier 1992, 1993).

En las elecciones que los alfareros realizan a lo largo del proceso de producción confluyen elementos aprendidos en contextos de enseñanza primaria, otros inventados y algunos copiados de otros alfareros. Asimismo, aspectos como quiénes son los agentes involucrados en la producción, a quiénes está destinado el objeto a elaborar, en qué contextos se desarrolla esta actividad, cuáles son las características y la disponibilidad de las materias primas utilizadas, qué mitos y tabúes son parte del proceso de manufactura, son solo algunos de los factores que afectan la dimensión estilística del comportamiento técnico $y$, por lo tanto, tienen consecuencias sobre las características que va adquiriendo el objeto en cada etapa de la producción. De este modo, la tecnología de manufactura y consecuentemente el conjunto de elecciones tomadas en la producción, deben ser entendidas dentro de la dinámi- ca social mayor de la que forman parte (Lemonnier 1992; Dietler y Herbich 1998; Gosselain 1998; Stark 1999; Mahias 2002).

El análisis de esta multiplicidad de factores que conforman las prácticas de producción se limita cuando la evidencia disponible es solo el registro arqueológico conformado por piezas cerámicas o fragmentos de las mismas. Sin embargo, las técnicas de elaboración utilizadas por los artesanos generan patrones materiales discernibles como consecuencia de elecciones compartidas (Dobres y Hoffman 1994; Dietler y Herbich 1998). De este modo, el estudio de las prácticas de producción puede abordarse desde el registro arqueológico a través de la identificación de modos de hacer particulares o estilos tecnológicos, perspectiva que en los últimos años se ha incrementado considerablemente (Goodby 1998; Stark et al. 1998; Chilton 1999; Sanhueza 2004; Feely 2010; Pereyra Domingorena 2010; Puente 2011b, entre otros). La unidad de análisis utilizada - piezas completas, fragmentos o lotes de fragmentos-, así como los atributos seleccionados para ser estudiados y las herramientas analíticas empleadas para ello, variaron de acuerdo a la pregunta de investigación y a las características particulares de los conjuntos estudiados.

En este trabajo se considera que una manera adecuada de abordar el estudio de las prácticas de producción alfarera del pasado es a través de un análisis holístico de los conjuntos cerámicos recuperados, sean fragmentos de piezas o ejemplares enteros (Dietler y Herbich 1998; Stark et al. 1998). En este sentido, se requiere un acercamiento que integre los atributos que se nos presentan como claramente visibles en la pieza terminada (forma, color, tratamiento de superficie, representaciones plásticas) con aquellos que están ocultos a nuestra percepción visual, en el sentido que requieren de una intervención particular para ser estudiados, como por ejemplo las pastas (Falabella et al. 2002). Ambas clases de atributos, en tanto fenómenos físicos observables y repetitivos, permiten realizar inferencias sobre las técnicas utilizadas en la manufactura de la alfarería y así, a través de ellas, conocer ciertas elecciones realizadas por los ceramistas a lo largo de la cadena operativa (Rye 1981).

En síntesis, dado que las cosas son la objetivación de relaciones sociales, el estudio de dichas relaciones puede ser 
abordado a partir del examen de similitudes y diferencias en la naturaleza material y contextual de los objetos (Jones 2001). En este sentido, un análisis interrelacionado de los aspectos aquí mencionados como visibles y ocultos de la alfarería es una vía de análisis pertinente para investigar las prácticas de producción y en este caso en particular, aquellas prácticas en las que uno de los propósitos fue generar un conjunto de piezas que comparten ciertas características estéticas, ${ }^{2}$ y a las que hoy agrupamos bajo un estilo cerámico particular.

\section{* Características generales de los sitios y ESTRATEGIAS DE FORMACIÓN DE LA MUESTRA}

El valle del Bolsón se encuentra ubicado en el Departamento de Belén, Provincia de Catamarca (Argentina), entre los $26^{\circ} 52^{\prime}$ a $27^{\circ}$ latitud sur y los $66^{\circ} 41^{\prime}$ a $66^{\circ} 49^{\prime}$ longitud oeste. Se orienta en sentido norte-sur siguiendo el curso del río El Bolsón, cuya extensión es de $20 \mathrm{~km}$ (Figura 1). Según la caracterización ambiental y condiciones productivas establecidas por Aschero y Korstanje (1993), se trata de un "valle alto", debido a que se encuentra emplazado entre los 2.500 y 2.900 m.s.n.m. y presenta condiciones para la producción de tubérculos microtérmicos y el pastoreo de llamas. Dada su ubica-

\footnotetext{
2 Se toma el concepto de estética desde la perspectiva de la Antropología del Arte -como una práctica que involucra el sentido de la percepción- desvinculada de las referencias de "belleza" de obras de arte. La percepción es una construcción social, por ello, la significación y el efecto que produce la dimensión estética de los objetos no están anclados en el objeto o en un atributo particular del mismo, sino que dependen del contexto histórico cultural específico en el cual se produce la interacción entre los individuos mediados por los objetos (Gell 1998; Alberti 2001; Gosden 2001; Jones 2001; Saunders 2001). Más allá de las valoraciones estéticas que generaron las piezas Belén en el pasado -en los múltiples contextos de producción, circulación y consumo en los que participaron- quienes elaboraron estas piezas reprodujeron un patrón estético que hoy estudiamos a través de un número de recursos estilísticos, como son la estructura morfológica, el diseño, el color, etc. A pesar de la variabilidad existente en estos aspectos entre los ejemplares, en su percepción se asimila lo diverso y en ello reside parte del poder evocador de estos objetos en tanto agentes activos en la interacción social. Por eso, en este trabajo con el término "características estéticas" hago referencia a las cualidades formales o visibles discutidas en el texto y concretamente dirijo mi atención hacia las prácticas de producción y los agentes involucrados en ellas.
}

ción, es un área transicional entre el ambiente de Puna (3400 m.s.n.m.) y de valles (1800 m.s.n.m.), razón por la cual se considera que funcionó como zona de interacción y tránsito entre ambientes diferenciados, del mismo modo que fue utilizado para la explotación de recursos diferenciados (Korstanje y Aschero 1996: 202).

Las ocupaciones de momentos prehispánicos tardíos en el valle se clasifican en asentamientos permanentes y otros vinculados a prácticas de tránsito y movilidad interregional. Cabe mencionar que hasta el momento no se ha recuperado evidencia incaica en la región pero hay registros de ocupación entre los siglos XV y XVII (Quiroga 2009a, 2009b Ms). Por este motivo y considerando la información disponible en dos valles vecinos, el valle de Hualfín y el valle de Santa María, bajo la categoría de "tardío prehispánico" hago referencia a un lapso temporal comprendido entre ca. 900-1600 DC y, por lo tanto, más extenso que el tradicionalmente utilizado en las periodificaciones establecidas para el NOA, cuyo límite superior se establece en 1480 DC a partir de la penetración incaica en el NOA (González 1963; Núñez Regueiro 1974). La muestra cerámica aquí trabajada fue recuperada en tres sitios de características diversas:

1) "LaAngostura" es un asentamiento del tipo agregado de carácter residencial y agrícola ubicado en el sector sur del Valle del Bolsón. A partir de un fechado radiocarbónico (390 \pm 70 AP, calibrado en rango de 10: 1460-1514 DC; 1542-1624 DC), su planta arquitectónica y la cerámica superficial y de excavación, el sitio es atribuido a ocupaciones post-formativas ${ }^{4}$ (Quiroga 2010a). El sitio presenta sectores de ocupación espacialmente discontinuos ubicados sobre los extremos de dos conos de deyección y

3 En el Valle de Hualfín, los fechados radiocarbónicos extienden la ocupación tardía hasta mediados del siglo XVII (Wynveldt 2006: tomo II, 176). Asimismo, en el valle de Santa María Tarragó y Nastri señalan que la categoría de Desarrollos Regionales si bien resulta operativa, abarca un amplio lapso cronológico en el que debieron sucederse numerosas transformaciones sociales y políticas que se ven oscurecidas por la reocupación de los sitios durante más de 600 años, incluyendo momentos de ocupación incaica y colonial temprana. De este modo, los testimonios materiales de estas ocupaciones se acumularon sin solución de continuidad (Tarragó y Nastri 1999: 262).

4 Quiroga (2002) utiliza esta unidad para hacer referencia a los períodos de Desarrollos Regionales, Inca e Hispano-Indígena según los esquemas de periodificación vigentes para el área. 


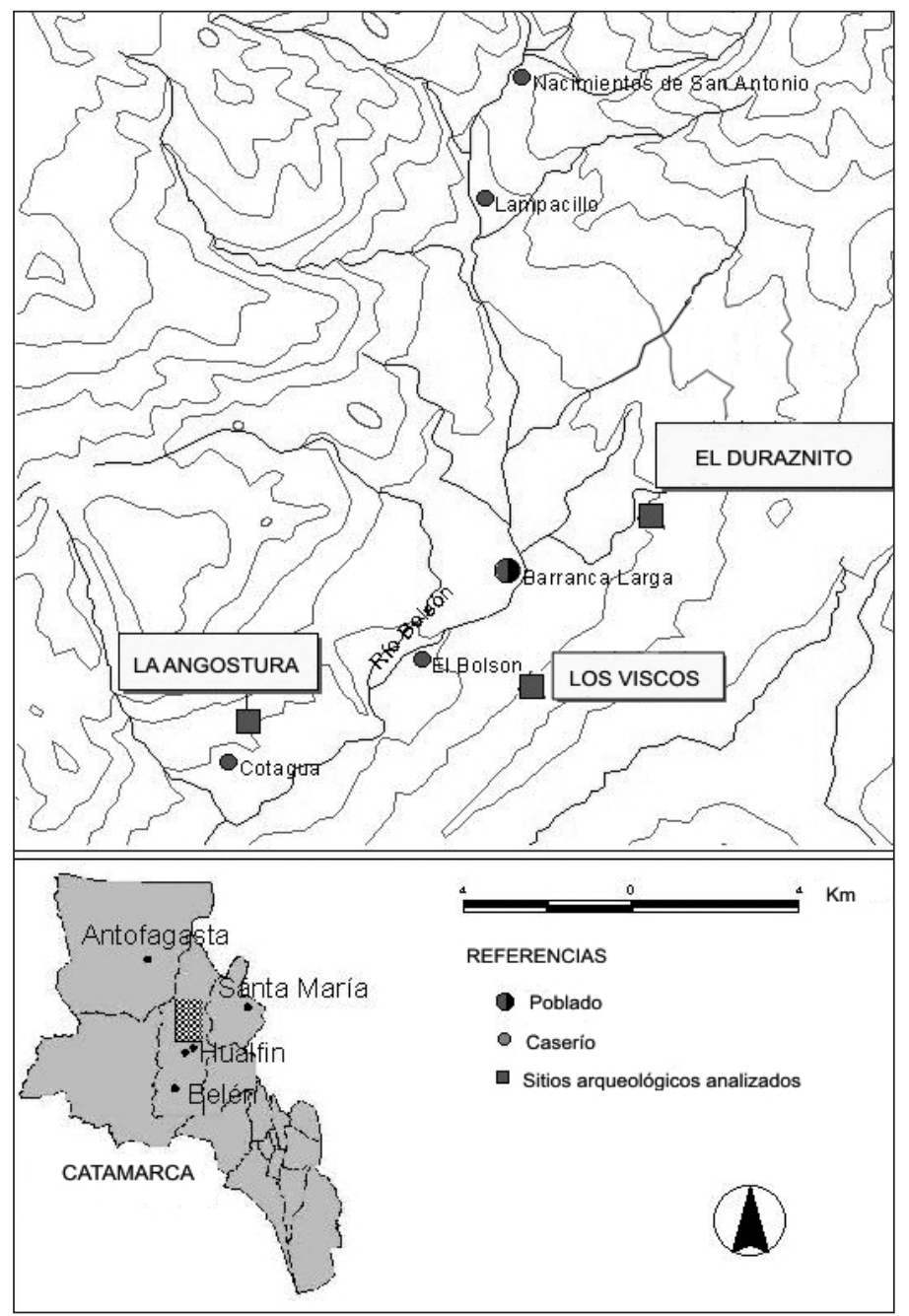

Figura 1. Mapa del valle del Bolsón con la ubicación de los sitios trabajados.

se caracteriza por la integración de los espacios residenciales y agrícolas, es decir, el lugar de residencia se orientó hacia el control físico y material de las áreas productivas (Quiroga 2002, 2004a Ms, 2004b, 2007a). De este modo, el carácter agregado del sitio y su diseño arquitectónico responden a una necesidad de control del agua y la tierra, recursos claves en una sociedad agrícola (Quiroga $2007 \mathrm{~b} \mathrm{Ms}$ ). Cabe mencionar que en un sitio cercano ( $L a$ Angostura Sector D) se obtuvo un fechado radiocarbónico semejante de $430 \pm 60$ AP (LP- 2219, calibrado en rango de 1б: 1443-1510 DC; 1554-1555 DC; 1575-1621 DC) (Quiroga 2010a). Esta tendencia de ocupaciones tardías es coherente en una escala macro regional con los fecha- dos obtenidos para el valle de Hualfín, evidenciando que estos asentamientos fueron habitados incluso hasta mediados de siglo XVII (Wynveldt 2006, 2008).

El conjunto cerámico aquí analizado es el resultado de distintas estrategias de muestreo, en las que se incluyen recolecciones superficiales exhaustivas y excavaciones estratigráficas en sectores extramuros y en recintos, realizadas por Quiroga y Carrera entre los años 1998 y 2003.

2) "El Duraznito" se encuentra ubicado en el sector central del valle, aproximadamente a $13 \mathrm{~km}$ de distancia de $\mathrm{La}$ Angostura. Se trata de un asentamiento emplazado en la 


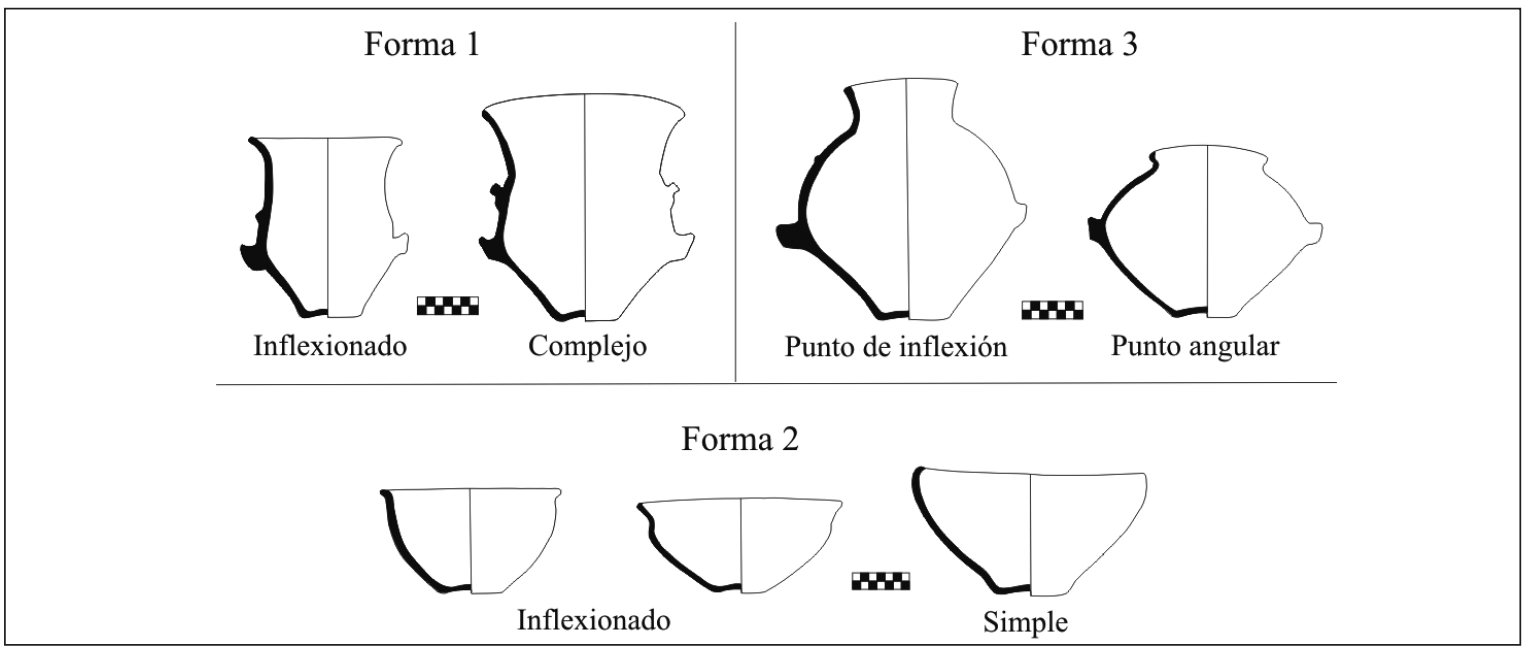

Figura 2. Variedades morfológicas representativas de la diversidad de piezas Belén.

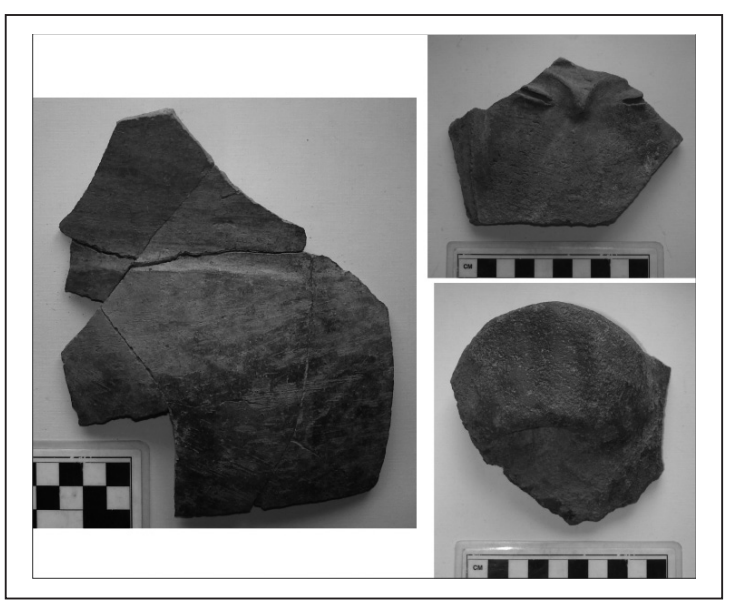

Figura 3. Fragmentos correspondientes a piezas de la Forma 1 y 3.

cima de un "jasi", limitado por un prominente precipicio y al cual, actualmente, es posible llegar solo por un sector de muy difícil acceso. Por sus características de emplaza-

\footnotetext{
5 Los lugareños denominan "jasi” a los badlands o zonas desnudas de vegetación que corresponden a la Formación El Cajón. Ésta es una formación donde predominan las tobas y desde el punto de vista productivo no es favorable para el asentamiento humano, aunque las terrazas fluviales, conos y otras formas asociadas con flujos fluviales y pluviales son ocupadas para el cultivo (Quiroga y Korstanje 2005).
}

miento, se plantea que su ubicación se relaciona con estrategias de defensa en momentos de conflicto regional y/o interregional (Quiroga y Korstanje 2005). Hasta el momento no se dispone de fechados absolutos, ${ }^{6}$ sin embargo, dado el emplazamiento del sitio, su planta arquitectónica y la cerámica recuperada en superficie y en excavación, se plantea que al igual que el sitio La Angostura, el Duraznito es un asentamiento vinculado a ocupaciones del lapso temporal correspondiente al tardío prehispánico.

Este asentamiento, recién comenzó a ser estudiado en el año 2007 por el equipo de investigación dirigido por Quiroga. El material cerámico recuperado en el sitio proviene de recolecciones superficiales y de sondeos realizados en sectores residenciales y en espacios identificados funcionalmente como patios (Quiroga 2010a).

3) "Los Viscos" está ubicado geográficamente entre los dos asentamientos recién mencionados. Este sitio presenta características que lo asocian a actividades de tránsito y movilidad interregional. Se trata de un alero de grandes dimensiones $\left(380 \mathrm{~m}^{2}\right)$ ubicado en una quebrada de difícil acceso (Korstanje y Würschmidt 1999; Korstanje 2005, 2007). A través de recolecciones superficiales y excavaciones estratigráficas, se recuperaron diversos ítems materiales, entre los que se destacan muros entramados de

\footnotetext{
${ }^{6}$ Los fechados se encuentran en proceso de análisis en el LATYR (Argentina).
} 


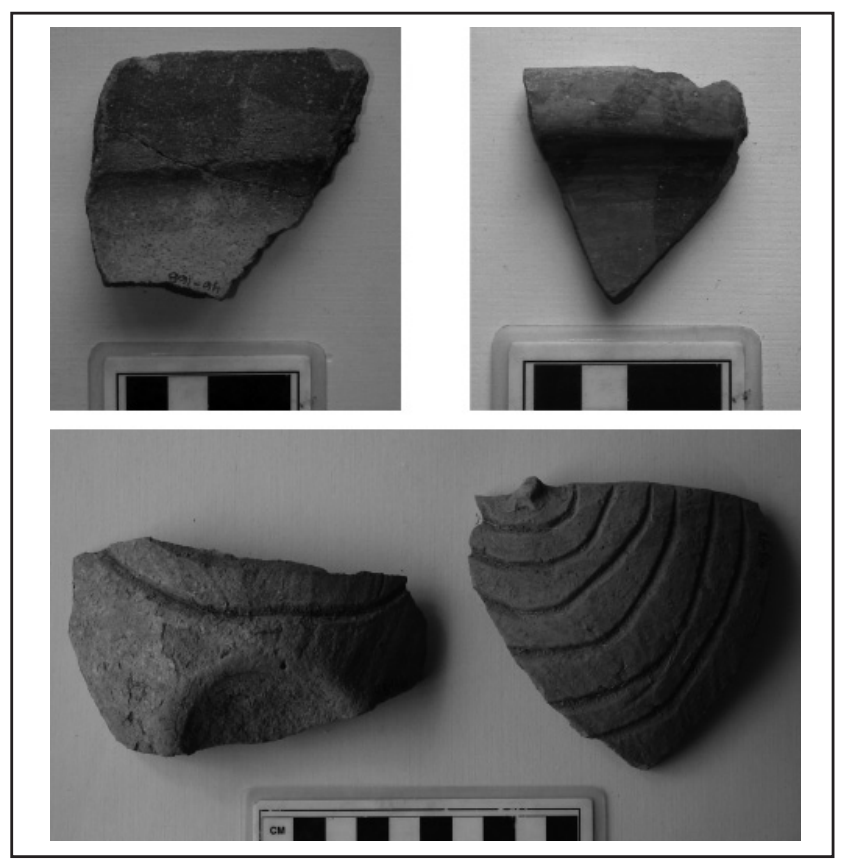

Figura 4. Fragmentos correspondientes a piezas de la Forma 2, presentando contorno simple e inflexionado.

cortadera y cardón, emplumaduras, pigmentos, puntas de proyectil confeccionadas en hueso, calabazas pirograbadas, cerámica, etc. Los fechados radiocarbónicos indican un rango temporal de ocupación amplio, entre 350 AC y 1360 DC (Korstanje 2005).

\section{* La alfarería de estilo Belén del valle DEL Bolsón}

La alfarería identificada como de estilo Belén es uno de los conjuntos cerámicos que predominan junto con la cerámica ordinaria en los sitios tardíos del valle. Tomando como referencia las clasificaciones previamente establecidas junto con Quiroga en los estudios realizados sobre piezas completas correspondientes a la colección Schreiter? (Puente y Quiroga 2007a, 2007b; Quiroga y Puente 2007a), se reconoció que las piezas recuperadas en el Valle del Bolsón representan la variabilidad estética tradicionalmente identificada para dicha unidad estilística. Específicamente con respecto a los tratamientos de

7 La colección se encuentra depositada en el Instituto de Arqueología y Museo de la Universidad Nacional de Tucumán (Argentina). superficie, si bien pueden variar según el sector y la superficie de la pieza, predominan los ejemplares que recibieron un tratamiento pulido y en menor medida alisado y bruñido. A nivel morfológico, se identifican ejemplares que denominamos como Forma 1, Forma 2 y Forma 3 (Puente y Quiroga 2007b) (Figura 2).

Las piezas de las Formas 1 y 3 , tradicionalmente conocidas como urnas y cántaros respectivamente, son difíciles de diferenciar a partir de material fragmentario dado que en ambos casos las características generales de la base, asas y borde son similares y la distinción principal se da por la altura del cuello (menor en la Forma 3) y la ubicación del diámetro máximo (Forma 1: en la boca; Forma 3: en el punto de unión cuerpo-base), aspectos posibles de observar solo en muestras poco fragmentadas (Puente y Quiroga 2007b). Por estos motivos, en algunos casos hago referencia a la categoría Forma 1-3. Con respecto a la Forma 2 (pucos), se identificaron variedades de contorno inflexionado con borde evertido y de contorno simple con borde invertido. Algunos fragmentos pertenecientes a ejemplares de las distintas formas mencionadas poseen diseños grabados en la superficie externa (Figuras 3 y 4 ). 


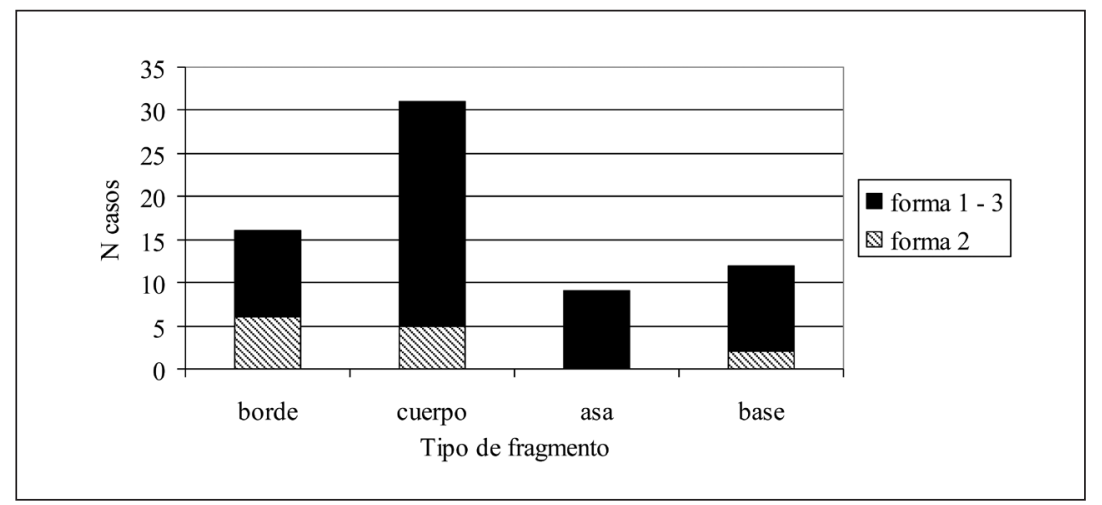

Figura 5. Frecuencia de fragmentos según sector de la pieza analizados microscópicamente.

La muestra analizada con microscopio petrográfico se compone de 68 fragmentos: 40 del sitio La Angostura, 26 del sitio El Duraznito y 2 del sitio Los Viscos. Cada uno de ellos corresponde a una pieza diferente y representan la variabilidad de pastas identificadas previamente con lupa binocular, así como la diversidad morfológica y de tratamiento de superficie registrada en el conjunto. Asimismo, se analizaron fragmentos correspondientes a distintos sectores de la pieza (Figura 5).

\section{* Caracterización petrográfica}

\section{Procedimientos analíticos y variables observadas}

Las observaciones se realizaron con el microscopio Leica DM EP sobre láminas delgadas $(0,03 \mathrm{~mm})$ que fueron cortadas orientando los fragmentos de modo perpendicular al borde o base de la pieza. El estudio realizado es cualitativo y cuantitativo. Las variables analizadas fueron seleccionadas tomando como referencia los trabajos de Courtois (1976), Cremonte (1996) y Freestone (1991) y se clasifican de la siguiente manera:

\section{- Material antiplástico (superior a 0,025 mm):}

- Naturaleza mineralógica: se identifican cristaloclastos (fragmentos de cristales minerales) y litoclastos (fragmentos de roca). Estos últimos se caracterizan de modo general en piroclásticos, volcánicos, graníticos, metamórficos y sedimentarios, según sea su origen. Para la identificación mineralógica se utiliza como referencia el manual de mineralogía Kerr (1965). Además se identifica la presencia de antiplástico de tipo antrópico como es el caso de tiesto molido.

- Esfericidady redondez: se determinan según el gráfico de estimación visual de Barraclough (1992) publicado en Orton et al. (1997: 268).

- Tamaño: clasificado según la escala de Wentworth, ${ }^{8}$ en: limo grueso (0,031-0,062 $\mathrm{mm}$ ) arena muy fina $(0,063-0,125 \mathrm{~mm})$, arena fina $(0,126-0,25 \mathrm{~mm})$, arena mediana $(0,26-0,5 \mathrm{~mm})$ arena gruesa $(0,55-1$ $\mathrm{mm}$ ) arena muy gruesa (1,05-2 $\mathrm{mm})$.

- Orientación.

- Cavidades/poros: forma general y tamaño (en mm).

- Estructura del fondo de pasta. Se clasifica según las categorías propuestas por Courtois (1976: 12-14):

- Sudolepidoblástica: masa de laminillas de micas detríticas abundantes y muy pequeñas unidas por una escasa fracción de arcilla;

- Criptofilitosa: matriz arcillosa muy cementada en la que no es posible identificar las microlaminillas de micas;

- Microgranosa: grandes cantidades de microcristales

${ }^{8}$ La tabla fue extraída del trabajo de Adams y colaboradores (1997). 


\begin{tabular}{|c|c|c|c|c|c|c|c|c|c|c|c|c|c|}
\hline \multirow{2}{*}{ Muestra } & \multicolumn{13}{|c|}{$\%$} \\
\hline & Antipl. & poros & matriz & V.V & $\mathrm{QZ}$ & FK & PLA & BIO & AN & L.V & L.GR & L.M & TM \\
\hline 1 & 37,93 & 26,41 & 35,66 & 9,02 & 12,41 & 5,41 & 1,58 & 2,93 & 0,45 & 2,48 & 1,12 & 0,44 & $\mathrm{O}$ \\
\hline 2 & 50,58 & 13,04 & 36,38 & 10,98 & 14,41 & 4,34 & 4,11 & 3,43 & 1,14 & 2,51 & 3,89 & 2,28 & $\mathrm{o}$ \\
\hline 3 & 38,65 & 21,44 & 39,91 & 4,88 & 9,55 & 7,21 & 3,82 & 0,84 & 1,48 & 3,18 & 0,84 & 1,05 & o \\
\hline 4 & 37,19 & 21,64 & 41,17 & 3,76 & 13,17 & 4 & 4 & 0,7 & 0,7 & 6,11 & 0,94 & 1,4 & 0 \\
\hline 5 & 46,38 & 12,17 & 41,45 & 12,41 & 12,64 & 3,98 & 4,91 & 3,04 & 0,46 & 3,74 & 0,23 & 0,46 & o \\
\hline 6 & 45,07 & 12,53 & 42,4 & 6,02 & 14,69 & 2,4 & 5,78 & 2,65 & 0,96 & 5,06 & 1,92 & 0,24 & o \\
\hline 7 & 39,75 & 15,93 & 44,32 & 5,89 & 7,2 & 3,49 & 5,02 & 2,83 & 1,74 & 2,62 & 4,58 & 3,26 & o \\
\hline 8 & 46,01 & 8,92 & 45,07 & 12,91 & 9,85 & 3,99 & 6,33 & 2,58 & 0,93 & 4,46 & 0,46 & 0,69 & o \\
\hline 9 & 44,43 & 9,76 & 45,81 & 9,3 & 10,23 & 4,18 & 3,02 & 2,55 & 2,79 & 6,51 & 2,32 & 0,69 & o \\
\hline 10 & 42,02 & 13 & 44,98 & 10,87 & 11,08 & 1,49 & 4,9 & 4,69 & 1,27 & 2,34 & 1,27 & 1,48 & o \\
\hline 11 & 37,57 & 16,02 & 46,41 & 5,74 & 11 & 3,11 & 5,02 & 1,67 & 0,95 & 3,82 & 3,58 & 1,18 & o \\
\hline 12 & 45,15 & 7,99 & 46,86 & 9,71 & 12,74 & 3,23 & 3,23 & 3,67 & 0,86 & 6,04 & 1,07 & 0,64 & o \\
\hline 13 & 41,72 & 10,98 & 47,3 & 9,41 & 9,86 & 2,46 & 2,69 & 2,91 & 0,67 & 4,03 & 2,69 & 2,9 & o \\
\hline 14 & 42,03 & 10,56 & 47,41 & 10,09 & 14,08 & 1,87 & 10,34 & 3,75 & 1,64 & 3,99 & 0 & 0,23 & 0 \\
\hline 15 & 43,54 & 8,62 & 47,84 & 7,75 & 15,51 & 1,29 & 4,31 & 2,58 & 1,07 & 3,62 & 3,01 & 0,86 & o \\
\hline 16 & 38,92 & 12,39 & 48,69 & 8,47 & 10,21 & 4,34 & 1,95 & 1,52 & 1,08 & 4,78 & 0 & 1,07 & o \\
\hline 17 & 36,12 & 15,04 & 48,84 & 1,38 & 7,68 & 5,09 & 6,01 & 0,23 & 1,38 & 1,62 & 4,39 & 3,15 & 0 \\
\hline 18 & 38,77 & 12,32 & 48,91 & 12,12 & 9,95 & 1,08 & 1,51 & 2,16 & 0,86 & 4,32 & 0,43 & 0,43 & 0 \\
\hline 19 & 45,49 & 4,97 & 49,54 & 9,95 & 18,09 & 1,58 & 7,01 & 2,03 & 0,9 & 2,26 & 0,45 & 0,45 & o \\
\hline 20 & 40,83 & 9,52 & 49,65 & 13,83 & 8,84 & 2,26 & 5,66 & 1,81 & 0,68 & 3,62 & 0,45 & 0,44 & 0 \\
\hline 21 & 39,25 & 10,16 & 50,59 & 13,47 & 8,03 & 3,3 & 2,6 & 3,54 & 0,7 & 3,07 & 0,23 & 0,23 & 0 \\
\hline 22 & 31,01 & 18,38 & 50,61 & 5,16 & 7,64 & 2,72 & 1,03 & 4,13 & 1,65 & 2,72 & 0,82 & 1,44 & 0 \\
\hline 23 & 38,47 & 9,5 & 52,03 & 12,21 & 9,5 & 2,94 & 3,61 & 1,58 & 0,9 & 3,84 & 0,9 & 0,67 & O \\
\hline 24 & 40,25 & 7,2 & 52,55 & 10,23 & 9,3 & 1,86 & 4,18 & 4,88 & 1,16 & 2,55 & 1,16 & 0,69 & O \\
\hline 25 & 38,22 & 7,78 & 54 & 5,94 & 11,44 & 2,05 & 5,94 & 1,37 & 1,6 & 4,11 & 0,45 & 0,22 & 0 \\
\hline 26 & 39,84 & 5,36 & 54,8 & 8,5 & 8,72 & 4,25 & 7,38 & 1,56 & 0,67 & 1,34 & 1,56 & 0,22 & O \\
\hline 27 & 41,69 & 2,96 & 55,35 & 13,66 & 12,3 & 2,05 & 2,27 & 2,73 & 0,22 & 4,55 & 0,45 & 0,67 & o \\
\hline 28 & 37,48 & 5,88 & 56,64 & 10,89 & 9,15 & 2,61 & 2,39 & 1,15 & 1,08 & 4,35 & 0,43 & 0,42 & 0 \\
\hline 29 & 40,58 & 2,66 & 56,76 & 7,98 & 11,3 & 3,1 & 4,65 & 1,77 & 1,33 & 3,54 & 1,33 & 2,2 & O \\
\hline 30 & 28,62 & 13,23 & 58,15 & 7,8 & 5,43 & 4,49 & 0,94 & 2,6 & 0,7 & 2,6 & 0,2 & 0,9 & 0 \\
\hline 31 & 34,53 & 7 & 58,47 & 7 & 6,26 & 5,7 & 1,83 & 0,54 & 0,72 & 6,26 & 0,54 & 1,44 & 0 \\
\hline 32 & 33,79 & 6,26 & 59,95 & 14,54 & 8,05 & 2,23 & 0,89 & 2,02 & 0,22 & 3,35 & 0 & 0 & 0 \\
\hline 33 & 33,01 & 4,1 & 62,89 & 7,03 & 9,37 & 1,75 & 1,75 & 0,58 & 1,56 & 7,81 & 0 & 0,58 & 0 \\
\hline 34 & 33,41 & 3,44 & 63,15 & 10,16 & 8,71 & 3,62 & 1,63 & 1,99 & 0,54 & 4,53 & 0,18 & 0,36 & 0 \\
\hline 35 & 26,8 & 6,7 & 66,5 & 5 & 9,5 & 3,2 & 1 & 2,03 & 0,5 & 1 & 1 & 0,5 & 0 \\
\hline 36 & 30,59 & 2,29 & 67,12 & 8,27 & 7,35 & 2,29 & 2,75 & 1,14 & 0,91 & 3,67 & 0 & 0,44 & 0 \\
\hline 37 & 26 & 6 & 68 & 7,7 & 11 & 1,5 & 0,5 & 0 & 0,2 & 2,7 & 0,7 & 0,7 & 0 \\
\hline 38 & 25,63 & 3,73 & 70,64 & 3,73 & 6,96 & 2,23 & 1,2 & 4,22 & 0,24 & 0,99 & 0,49 & 2,73 & 0 \\
\hline 39 & 21 & 8 & 71 & 3,6 & 3,4 & 1,2 & 0,6 & 1,2 & 1,2 & 3,8 & 0,6 & 0,4 & 4 \\
\hline 40 & 25,37 & 3,28 & 71,35 & 7,48 & 7,84 & 2 & 0,36 & 0,54 & 0,18 & 2,55 & 1,82 & 0,36 & 0 \\
\hline 41 & 26,46 & 4,33 & 69,21 & 5,6 & 4,83 & 1,53 & 6,11 & 2,54 & 1,02 & 1,02 & 0,25 & 1,53 & 0 \\
\hline 42 & 35,15 & 3,65 & 61,2 & 10,42 & 5,47 & 1,04 & 7,03 & 3,65 & 0,26 & 4,69 & 0,52 & 1,3 & 0 \\
\hline 43 & 35,72 & 3,81 & 60,47 & 9,94 & 8,67 & 2,54 & 2,33 & 4,86 & 1,27 & 1,48 & 0 & 3,81 & 0 \\
\hline 44 & 43,89 & 7,98 & 48,13 & 11,47 & 12,72 & 5,24 & 5,49 & 1,5 & 0 & 3,24 & 3,24 & 0 & o \\
\hline 45 & 46,33 & 5,12 & 48,55 & 10,24 & 13,59 & 5,79 & 3,34 & 2,45 & 0,45 & 3,79 & 4,01 & 2 & 0 \\
\hline 46 & 38,18 & 9,11 & 52,71 & 8,37 & 12,56 & 4,19 & 5,42 & 2,96 & 0,49 & 0,25 & 0,49 & 2,96 & 0 \\
\hline 47 & 24,66 & 3,39 & 71,95 & 0 & 9,28 & 4,52 & 7,24 & 0,23 & 0 & 0 & 0 & 2,71 & 0 \\
\hline 48 & 37,38 & 3,04 & 59,58 & 8,64 & 12,62 & 2,8 & 4,67 & 1,64 & 0,7 & 1,64 & 0 & 1,64 & 0 \\
\hline 49 & 29,38 & 6,96 & 63,66 & 11,34 & 4,12 & 2,06 & 4,12 & 1,29 & 0,26 & 1,29 & 1,29 & 2,84 & 0 \\
\hline 50 & 33,25 & 4,38 & 62,37 & 6,7 & 10,82 & 5,67 & 3,35 & 3,61 & 0,26 & 1,03 & 0 & 0,52 & 0 \\
\hline 51 & 39,18 & 5,53 & 55,29 & $31, \mathrm{O} 1$ & 2,16 & 0,48 & 3,61 & 0,96 & 0,24 & 0,48 & 0 & 0 & o \\
\hline 52 & 43,19 & 4,37 & 52,44 & 14,14 & 12,34 & 3,34 & 5,14 & 3,86 & 0 & 1,29 & 1,29 & 0 & o \\
\hline 53 & 33,5 & 4,65 & 61,85 & 10,76 & 10,51 & 3,67 & 4,4 & 0,73 & 0 & 0,98 & 0,24 & 0,49 & O \\
\hline 54 & 35,57 & 3,86 & 60,57 & 14,63 & 8,54 & 2,03 & 4,47 & 2,03 & 0,41 & 0,81 & 1,02 & 0 & 0 \\
\hline 55 & 27,58 & 5,75 & 66,67 & 1,72 & 6,03 & 2,3 & 2,3 & 2,01 & 0 & 1,15 & 0 & 0 & 7,76 \\
\hline 56 & 35,58 & 4,04 & 60,38 & 15,63 & 2,7 & 3,23 & 2,96 & 2,96 & 0,27 & 2,16 & 0,27 & 2,7 & 0 \\
\hline 57 & 37,22 & 4,05 & 58,73 & 0 & 7,59 & 5,82 & 5,06 & 14,43 & 0 & 1,77 & 1,01 & 1,01 & 0 \\
\hline 58 & 27,69 & 12,53 & 59,78 & 9,67 & 4,4 & 2,64 & 4,18 & 3,52 & 0,22 & 0,66 & 0 & 0,22 & O \\
\hline 59 & 41,97 & 11,03 & 47 & 13,67 & 13,43 & 3,36 & 5,28 & 1,2 & 0,24 & 0,72 & 0,96 & 1,44 & 0 \\
\hline 60 & 34,06 & 7,43 & 58,51 & 6,71 & 2,4 & 2,4 & 2,88 & 6,24 & 0 & 1,2 & 0,96 & 0 & 8,87 \\
\hline 61 & 43,9 & 10,25 & 45,85 & 8,54 & 10,73 & 5,61 & 8,78 & 4,63 & 0,49 & 1,71 & 0,98 & 0 & 0 \\
\hline 62 & 32,72 & 3,71 & 63,57 & 10,21 & 8,35 & 5,34 & 4,41 & 0,23 & 0,46 & 2,55 & 0 & 0,7 & 0 \\
\hline 63 & 29,31 & 4,68 & 66,01 & 4,43 & 9,11 & 4,68 & 4,43 & 0,99 & 0,25 & 1,97 & 0 & 0,74 & 0,74 \\
\hline 64 & 23,67 & 6,38 & 69,95 & 3,99 & 6,65 & 2,93 & 3,19 & 3,46 & 0,27 & 0,8 & o & 1,06 & 0 \\
\hline 65 & 34,92 & 7,54 & 57,54 & 9,5 & 6,98 & 4,47 & 5,87 & 2,51 & 0,28 & 1,96 & 0 & 0,56 & o \\
\hline 66 & 44,38 & 7,49 & 48,13 & 14,99 & 10,37 & 5,76 & 6,63 & 0,58 & 0 & 3,17 & 0,58 & 1,15 & o \\
\hline 67 & 25,31 & 6,94 & 67,75 & 7.35 & 1,63 & 0 & 4,9 & 0,82 & 2,45 & 4,08 & 0 & 1,63 & 0 \\
\hline 68 & 20,14 & 5,8 & 74,06 & 4,44 & 2,05 & $1, \mathrm{O} 2$ & 0,68 & 0,69 & 0,68 & 2,05 & o & 2,05 & 0 \\
\hline
\end{tabular}

Tabla 1. Análisis modal. Referencias: Antipl. (antiplástico), V.V (vidrio vesicular), QZ (cuarzo), FK (feldespato potásico), PLA (plagioclasa), BIO (biotita), AN (anfíbol), LV (lítico volcánico), L. GR. (lítico granítico), L.M (lítico metamórfico), TM (tiesto molido).

no arcillosos que por su tamaño pequeño no es posible identificarlos con exactitud. También se registró el color (observado sin polarizador) y la existencia o no de birrefringencia (con nicoles cruzados) en la matriz.

- Distribución modal de antiplástico (densidad), fondo de pasta y cavidades (porosidad): se realizó mediante point counter, tomando 400 mediciones - a distancias constantespor corte delgado.

\section{Las pastas de la cerámica Belén}

En primer lugar, con el propósito de analizar cómo se relacionaban las piezas entre sí en relación al tipo de inclusiones no plásticas presentes en sus pastas, se realizó un análisis de cluster considerando los 68 casos y 10 caracteres cuantitativos continuos correspondientes a la naturaleza de las inclusiones: vidrio vesicular, cuarzo monocristalino, feldespato potásico, plagioclasa, biotita, anfíbol, líticos volcánicos, líticos graníticos, líticos metamórficos y tiesto molido (Tabla 1). Para este análisis, se 


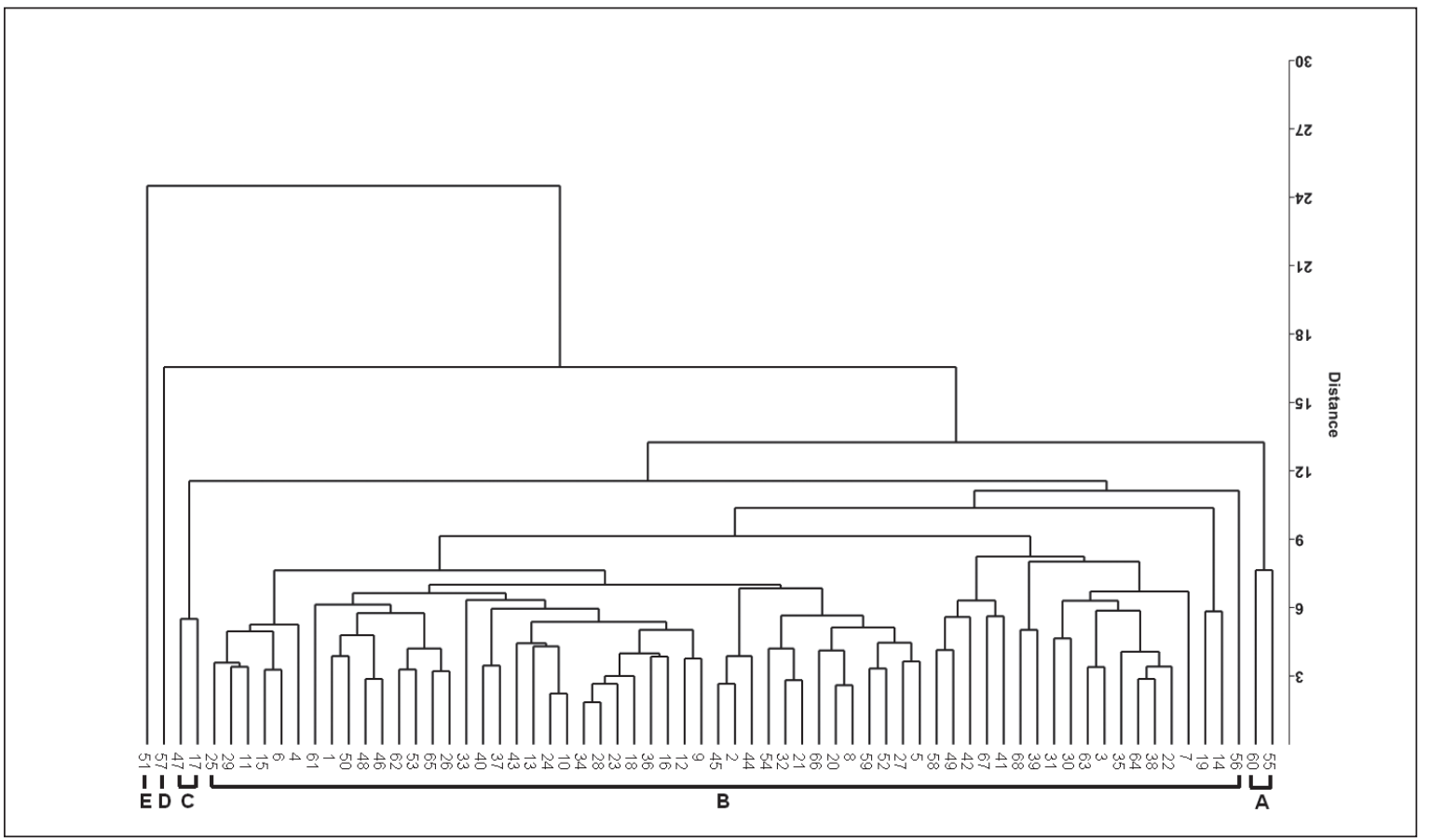

Figura 6. Dendograma según naturaleza de las inclusiones no plásticas.

utilizó el coeficiente de distancia euclídea y la técnica de pares agrupados (Shennan 1992). Asimismo, para evaluar los resultados alcanzados mediante este análisis, se calculó el coeficiente de correlación cofenética obteniendo un valor de 0,867 lo cual indica que el dendograma es una buena representación de la matriz de similitud generada en el análisis de cluster (Crisci y López Armegol 1983: 65). El tratamiento estadístico de los datos fue realizado utilizando de forma combinada los programas SPSS 15.0 y Past.

En el dendograma resultante (Figura 6) se distingue por un lado un conjunto principal (cluster B) conformado por 62 de las muestras analizadas y por otro, cuatro grupos (clusters A, C, D y E) que están conformados por uno o dos ejemplares cada uno y que se diferencian de distinta manera del conjunto mayor.

Cluster A. Se trata de dos ejemplares que fueron elaborados con la incorporación de tiesto molido, temperante ausente en la mayoría de las piezas. Estas pastas también poseen cantidades significativas de cuarzo monocristalino, feldespato potásico, plagioclasa, biotita, muscovita y vidrio vesicular. En proporciones inferiores se distinguen litoclastos volcánicos y graníticos. (Figura 7A).

Cluster B. Está conformado por la mayoría de las piezas estudiadas $(\mathrm{N}=62)$. Predominan de manera significativa los clastos y trizas de vidrio vesicular y clastos de cuarzo monocristalino. En segundo lugar, están presentes cristaloclastos de plagioclasa con macla polisintética, feldespato potásico, pequeñas laminillas de biotita y litoclastos volcánicos. Los cristaloclastos del grupo de los feldespatos -tanto la plagioclasa como el feldespato potásico-, se observan sin alteración y también con distintos grados de alteración a arcillas y sericita, diversidad que se presenta incluso en el mismo corte delgado. Por su parte, los litoclastos volcánicos están conformados por pequeñas laminillas de plagioclasa dispuestas de manera azarosa u orientada y en muchos casos se presentan junto a pequeños opacos de color negro o rojo (ferruginosos). En proporciones inferiores están presentes fragmentos de roca volcánica de textura microgranosa. En menor medida se observan todavía litoclastos graníticos, minerales opacos y líticos metamórficos de bajo grado. También es importante mencionar que práctica- 


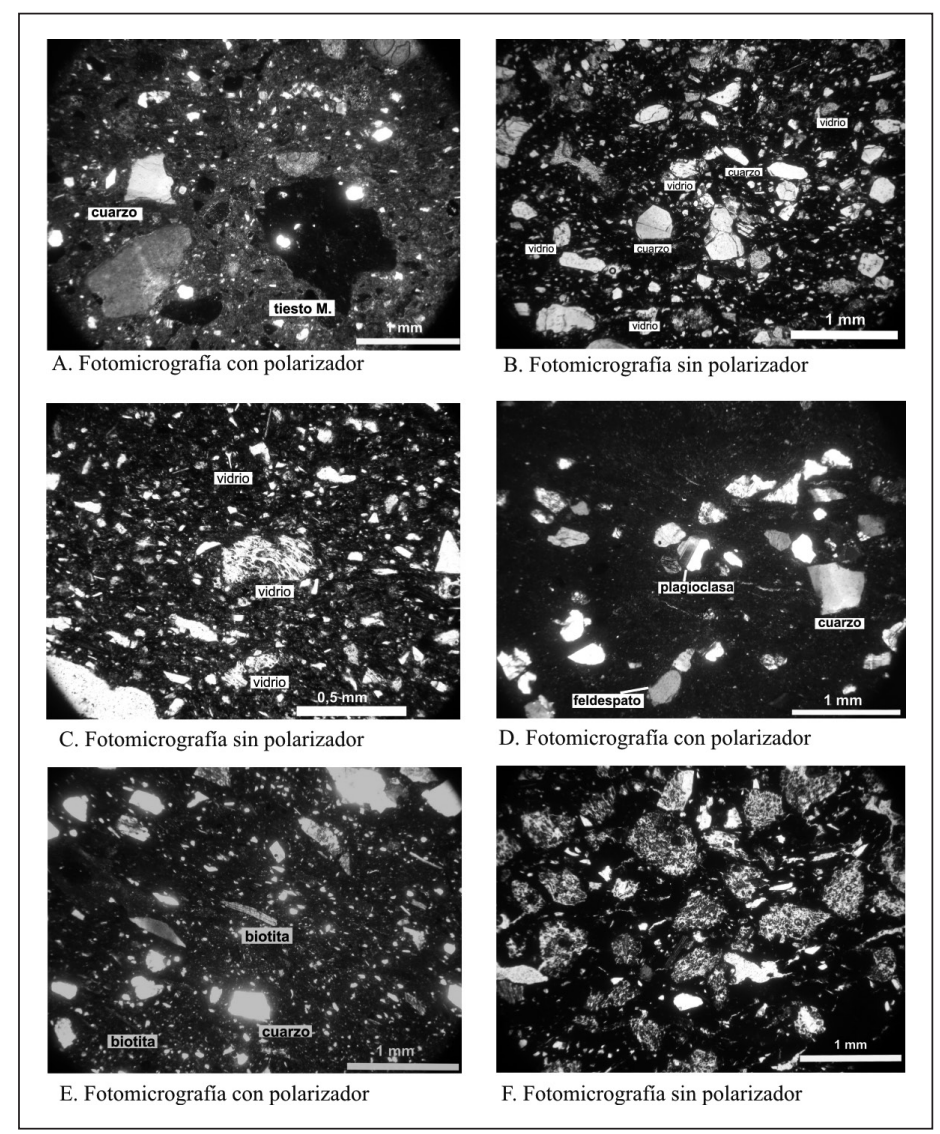

Figura 7. Fotomicrografías correspondientes a los distintos clusters.

mente en todos los cortes están presentes cristaloclastos de anfíboles, piroxenos y muscovita pero en porcentajes muy poco significativos (inferiores al 1\%). En el mismo sentido, en muchos ejemplares se identificaron cristaloclastos de microclino, epidoto, circón y clastos totalmente alterados (Figuras $7 \mathrm{~B}$ y $7 \mathrm{C}$ ).

Cluster C. Predominan los clastos de cuarzo monocristalino, plagioclasa con macla polisintética y feldespato potásico. A diferencia del cluster B, en estos ejemplares el vidrio vesicular está ausente o presente en muy bajos porcentajes, del mismo modo que los litoclastos volcánicos. En cambio, los litoclastos metamórficos y graníticos adquieren mayor jerarquía (Figura 7D).

Cluster D. Predominan pequeñas laminillas de biotita, cristaloclastos de cuarzo monocristalino, feldespato potásico y plagioclasa. Estos dos últimos están presentes con distintos grados de alteración a arcillas y sericita. En proporciones significativamente inferiores, se observan litoclastos volcánicos, graníticos y metamórficos y escasos cristaloclastos de muscovita. De igual manera que en los ejemplares del cluster $\mathrm{C}$, el vidrio vesicular está ausente y se observan bajos porcentajes de litoclastos volcánicos, graníticos y metamórficos (Figura $7 \mathrm{E}$ ).

Cluster E. Corresponde a un ejemplar que posee altos porcentajes de vidrio vesicular. Éste es prácticamente el único antiplástico presente en la pasta. En porcentajes significativamente inferiores, se observa cuarzo monocristalino, plagioclasa con macla polisintética, biotita, feldespato potásico, anfíbol y opacos. El vidrio está presente principalmente en forma de clastos que a veces incluyen cristales de plagioclasa, biotita, anfíbol u opacos. Algunos clastos de feldespato potásico y de plagioclasa poseen alteración a arcillas (Figura $7 \mathrm{~F}$ ). 
Cabe aclarar que en algunos de los cortes analizados se observan escasos ejemplares de grumos de arcilla, posiblemente como resultado de un mal amasado de la mezcla arcillosa durante su procesamiento.

En relación a las características de la estructura de fondo de pasta se observan las variedades microgranosa, seudolepidoblástica y criptofilitosa, en muchos casos combinadas entre sí. De este modo, las estructuras identificadas se clasifican de la siguiente manera:

- Seudolepidoblástica: 9 piezas

- Criptofilitosa: 3 piezas

- Microgranosa: 8 piezas

- Microgranosa - algo seudolepidoblástica: 9 piezas

- Criptofilitosa - algo microgranosa: 28 piezas

- Criptofilitosa con sectores seudolepidoblásticos: 11 piezas

Considerando el pequeño tamaño de los cristales o fragmentos de rocas que conforman las texturas microgranosas (inferior a $0,025 \mathrm{~mm}$ ), es posible plantear que estos elementos formaban parte de la mezcla arcillosa recolectada por el alfarero y utilizada en la elaboración de las piezas (Courtois 1976; Freestone 1991). De este modo, la diferencia entre las texturas microgranosas y las no microgranosas (criptofilitosas y seudolepidoblásticas) indican variabilidad en los aspectos texturales de las arcillas seleccionadas para la manufactura. La presencia de fondos de pasta criptofilitosos puede ser un indicio de que alcanzaron temperaturas de cocción mayores a las piezas con fondos de pasta no criptofilitosos, aspecto que estamos estudiando junto al Dr. Porto López (INTEMA-CONICET-UNMDP) a partir de tareas de calcinación y análisis de DRX (Porto López y Puente $2011 \mathrm{Ms}$ ).

En relación al tamaño de las inclusiones no plásticas, se identifican las siguientes tendencias: en 64 piezas predominan las de tamaño inferior a la arena gruesa. Considerando la diversidad presente, se establece la siguiente diferenciación: a. Pastas con inclusiones de tamaño poco seleccionado:

1) de limo grueso a arena mediana: 3 piezas

2) de arena muy fina a arena mediana: 6 piezas

3) de arena muy fina a gruesa: 2 piezas

b. Pastas con inclusiones de tamaño mejor seleccionado:

1) limo grueso y arena muy fina: 8 piezas

2) limo grueso y arena fina: 17 piezas

3) arena muy fina y arena fina: 5 piezas

4) arena mediana: 8 piezas

5) arena fina y arena mediana: 17 piezas

6) arena mediana y arena gruesa: 2 piezas

En todos los cortes se observó una combinación de cristaloclastos y litoclastos de esfericidad baja y alta y de forma angular, sub-angular, redondeada y sub-redondeada. En ninguno de los casos, se reconoce un predominio de formas angulares a partir de las cuales sea posible inferir la práctica de molienda de material lítico para ser luego agregado como antiplástico. Sin embargo, siguiendo la propuesta de Shepard (1957: 161) sobre la abundancia relativa y el tamaño de grano de las inclusiones no plásticas, planteo que en los ejemplares con antiplástico de tamaño poco seleccionado y en los que predominan arenas medianas a gruesas posiblemente el alfarero agregó el temperante a la mezcla arcillosa original.

En cuanto a la densidad y porosidad de las pastas, se realizó un análisis exploratorio de datos para determinar las características de distribución de la muestra. Al respecto, como se observa en la Figura 8, la densidad de las pastas varía significativamente entre $20,14 \%$ y $48,60 \%$, lo cual indica que algunas piezas se elaboraron con mayor carga de temperante que otras. El análisis exploratorio muestra que la distribución, si bien se acerca a la normalidad, posee una leve asimetría hacia la izquierda (coeficiente de asimetría: - 0,43 ) dada por la concentración de ejemplares cuya densidad es superior a la media $(36,20 \%)$. 


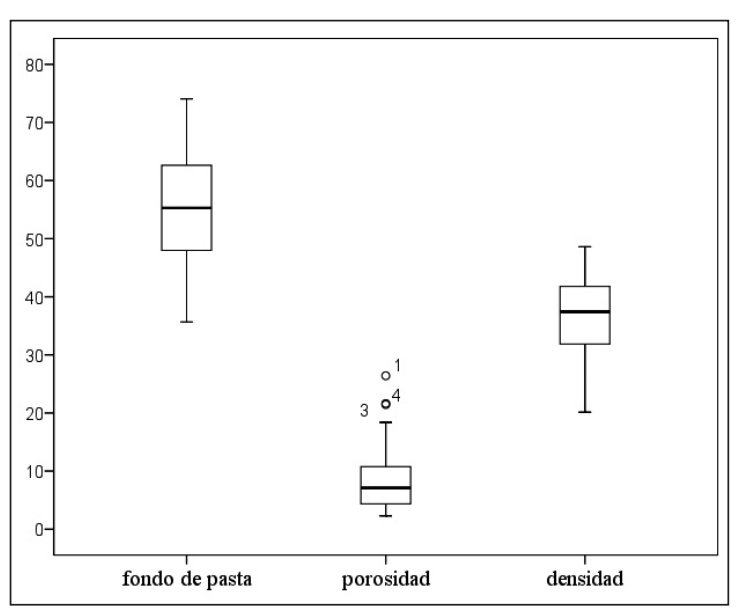

Figura 8. Diagrama de cajas según análisis modal de las pastas. Se compara la distribución de la densidad de inclusiones no plásticas, la porosidad y el fondo de pasta del conjunto analizado.

En relación a la porosidad, las pastas varían entre 2,29\% y $26,41 \%$. La distribución es asimétrica hacia la derecha (coeficiente de asimetría: 1,43) dada por la concentración de ejemplares con porosidad inferior a la media $(8,30 \%)$. Asimismo, se observan tres valores atípicos conformados por las pastas de mayor porosidad.

En síntesis, en el conjunto estudiado se destaca la semejanza en la naturaleza del antiplástico, pero se identifican diferencias en los modos de elaboración de las pastas, materializadas en los atributos de densidad, porosidad, tamaño y grado de selección de las inclusiones no plásticas y en las características del fondo de pasta.

\section{* ¿Producción local o alóctona? \\ AproximaCión DESDE LA PETROLOGÍA}

El análisis petrológico implica la comparación de la información composicional obtenida a partir del análisis petrográfico por cortes delgados de cerámica arqueológica y de sedimentos locales. De este modo, la identificación de la naturaleza del material antiplástico presente en la cerámica fue comparada con la misma información obtenida de un conjunto de sedimentos (arenas y arcillas) muestreados en el valle del Bolsón. El propósito de este cotejo fue determinar si la composición de los sedimentos locales presenta concordancia o no con la observada en la cerámica recuperada en los sitios del valle. Esta instancia de investigación brinda información sumamente útil y constituye una primera etapa en los estudios de procedencia (Shepard 1957; Stoltman 2001; Cremonte et al. 2007).

\section{Características geológicas del valle del Bolsón}

El valle del Bolsón presenta desde el punto de vista geológico un ambiente típico de Sierras Pampeanas. ${ }^{9}$ Los sitios arqueológicos estudiados, por su ubicación, se vinculan directamente con material de acarreo y con dos formaciones litológicas de origen terciario -El Aspero y El Cajón-, correspondientes al Grupo El Bolsón (MiocenoPlioceno), representadas por un conjunto de sedimentos continentales con intercalación de origen volcánico.

La formación El Aspero (complejo volcánico) está integrada por una facie lávica y una facie intrusiva, en donde se destacan elementos de origen piroclástico, brechas y tobas de naturaleza entre andesítica y basáltica (González Bonorino 1950; Turner 1973). En el valle, predomina la facie lávica formada por brechas (andesitas de color verde azulado, con numerosos fenocristales de anfíbol y plagioclasa) y tobas (plagioclasa básica, macladas, frescas, zonales; prismas de clinopiroxeno y de hornblenda). Con respecto a la Formación El Cajón (Araucanense), se compone de un conjunto de elementos clásticos y volcánicos que se superponen en concordancia sobre la formación anterior y está integrada por tufitas, sedimentos psamíticos y psefíticos. El material constitutivo es mayormente granítico (puede ser migmatítico), con rodados de pizarra cuarzosa, gneiss milonítico, micacitas y andesita. El sedimento limoso micáceo y con vidrio funciona como cemento. Se observan bancos de material tufítico y otros de material tobáceo. Estos últimos integrados por vidrio, plagioclasa, cuarzo y micas, entre otros (González Bonorino 1950; Turner 1973).

Por su parte, los depósitos de acarreo están constituidos por sedimentos arenosos con intercalaciones arcillosas y conglomeráticas dispuestas en terrazas (Turner 1973). Específicamente, el río El Bolsón, recurso hídrico principal

9 Su ubicación y descripción geológica corresponde a las hojas 11d, Laguna Blanca (escala 1:200.000) y 12d Capillitas (escala $1: 200.000$ ). 
del valle, acarrea de norte a sur material correspondiente a las formaciones El Cajón, Loma Corral y Chango Real. La formación Loma Corral (Precámbrico) está integrada por rocas metamórficas sin aporte magmático. Principalmente, se trata de esquistos, pizarras y filitas. Por su parte, la formación Chango Real (Precámbrico) está compuesta por granitos migmatíticos de tipo homogéneo y con anatexitas. ${ }^{10}$ Por otra parte, los cauces de ríos y arroyos temporarios, tributarios del río El Bolsón acarrean tanto desde el E como desde el O material de la formación El Aspero y de la formación El Cajón. Como resultado, en el río El Bolsón transporta sedimentos conformados por fragmentos de rocas y minerales de origen diverso: tobas, granitos migmatíticos, rocas sedimentarias, rocas volcánicas y rocas metamórficas.

\section{Petrografía de los sedimentos locales}

Con el propósito de identificar fuentes de materias primas -arcillas y antiplásticos- aptas para ser utilizadas en la manufactura alfarera y de establecer inferencias sobre la procedencia local o alóctona de la alfarería recuperada en la región, se complementaron dos estrategias de muestreo: 1) prospecciones geológicas a lo largo del sector sur y central del valle y, 2) información brindada por pobladores actuales. Como resultado se muestrearon diez fuentes de arcilla y cinco fuentes de sedimentos arenosos, los cuales fueron sometidos a estudios mineralógicos, químicos y experimentales (Puente zoloa; Puente 2011b). Por una cuestión de espacio, en esta oportunidad describiré específicamente las características de dos de los sedimentos arenosos analizados debido a que presentan importantes semejanzas con la naturaleza de las inclusiones no plásticas identificadas en la cerámica. ${ }^{11}$ Para el análisis microscópico de los sedimentos, cada muestra fue consolidada con resina y se elaboraron "pastillas"

\footnotetext{
${ }^{10}$ A modo de aclaración, cabe mencionar que los granitos migmatíticos son un complejo integrado por sedimentos metamorfizados con penetración ígnea. Estos afloramientos poseen amplias extensiones. En muestra de mano, se trata de un granito de grano grueso con abundante mica. Megascópicamente, es una roca de grano grueso a porfiroide en la que se observa microclino, plagioclasa, cuarzo, apatita, clorita y epidoto y la pasta está compuesta por cuarzo y feldespato (Turner 1973). La anatemitas son rocas mixtas con estructura esquistosa muy poco visible (Turner 1973).

${ }^{11}$ La descripción de todos los sedimentos muestreados puede ser consultada en Puente 2011b.
}

para poder realizar el corte delgado y la posterior observación. El análisis modal brindó los siguientes resultados (Tabla 2):

1. Sedimento de color blanco recuperado en un depósito estratificado que se extiende sobre la base de un jasi ubicado a los $27^{\circ} 00.292^{\prime}$ latitud sur $66^{\circ} 43.951^{\prime}$ longitud oeste. Como se observa en la Tabla 2, este depósito está conformado principalmente por sedimento de origen piroclástico identificado como vidrio vesicular y trizas vítreas. Algunos clastos están formados por vidrio vesicular y cristales de distintos minerales (cuarzo monocristalino y policristalino, plagioclasa, feldespato potásico, anfíbol, biotita y opacos). Los litoclastos volcánicos presentes en el sedimento son de características texturales diversas, algunos poseen matriz vítrea y microlaminillas de plagioclasa y otros, son de textura microgranosa. En relación al tamaño, predominan las arenas medianas, gruesas y finas, en ese orden. El grado de desgaste varía entre angular, subangular, sub-redondeada y de esfericidad baja (Figura 9).

2. Arena que acarrea el río El Bolsón. Predominan cristaloclastos de cuarzo monocristalino y en menor medida cuarzo policristalino. Esta diversidad implica que estos cristales provienen de rocas con origen litológico distinto. Con respecto a la plagioclasa, en su mayoría presenta macla polisintética y también hay cristales con extinción zonal, ambos característicos de ambientes volcánicos. Los litoclastos volcánicos presentan diferencias texturales, algunos poseen la matriz de textura microgranosa y con fenocristales de plagioclasa y biotita y, en otros casos, la matriz es de textura vítrea o formada por microlitos de plagioclasa y opacos, acompañados por fenocristales de plagioclasa, anfíboles, piroxenos u opacos característicos de rocas andesíticas y basálticas. Los litoclastos graníticos están formados por muscovita, plagioclasa (alterada a sericita), feldespato potásico, cuarzo, microclino y piroxeno. Con respecto a los litoclastos metamórficos están constituidos por: cuarzo, biotita, feldespato potásico (en algunos casos alterados a arcilla y sericita y en otros casos sin alteración) y muscovita. También se observan porcentajes significativos de clastos de vidrio vesicular como los característicos del sedimento 1. Como puede observarse, esta arena está conformada por fragmentos minerales y de roca provenientes de orígenes geológicos diferentes: volcánico, metamórfico, piroclástico (clastos y trizas de vidrio vesicular) y granítico o plutónico (Figura 10). 


\begin{tabular}{|c|c|c|c|c|c|c|c|c|c|c|c|c|c|c|c|c|c|}
\hline & \multicolumn{17}{|c|}{$\%$} \\
\hline & $Q z$ & Fk & Pla & Mic & Bio & Mu & $\mathrm{Cl}$ & An & $P x$ & Ep & Car & $\mathrm{Op}_{\mathrm{p}}$ & V.V & L.V & L.Gr & L.M & L.A \\
\hline 1 & 2,10 & 0,47 & 0,93 & - & 0,70 & - & - & 0,12 & - & - & - & - & 93,69 & 1,17 & - & 0,47 & 0,35 \\
\hline 2 & 20 & 6,22 & 12,44 & 2,44 & 2,00 & 0,22 & 0,22 & 0,22 & 1,56 & 0,67 & 0,89 & 0,22 & 9,11 & 12,44 & 9,78 & 15,78 & 5,78 \\
\hline
\end{tabular}

Tabla 2. Análisis modal. Referencias: Qz (cuarzo), Fk (feldespato potásico), Pla (plagioclasa), Mic (microclino), Bio (biotita), Mu (muscovita), Cl (clorita), An (anfíbol), Px (piroxeno), Ep (epidoto), Car (carbonato), Op (opaco), L.V (litoclasto volcánico), L.Gr (litoclasto granítico), L.M (litoclasto metamórfico), L.A (litoclasto alterado).

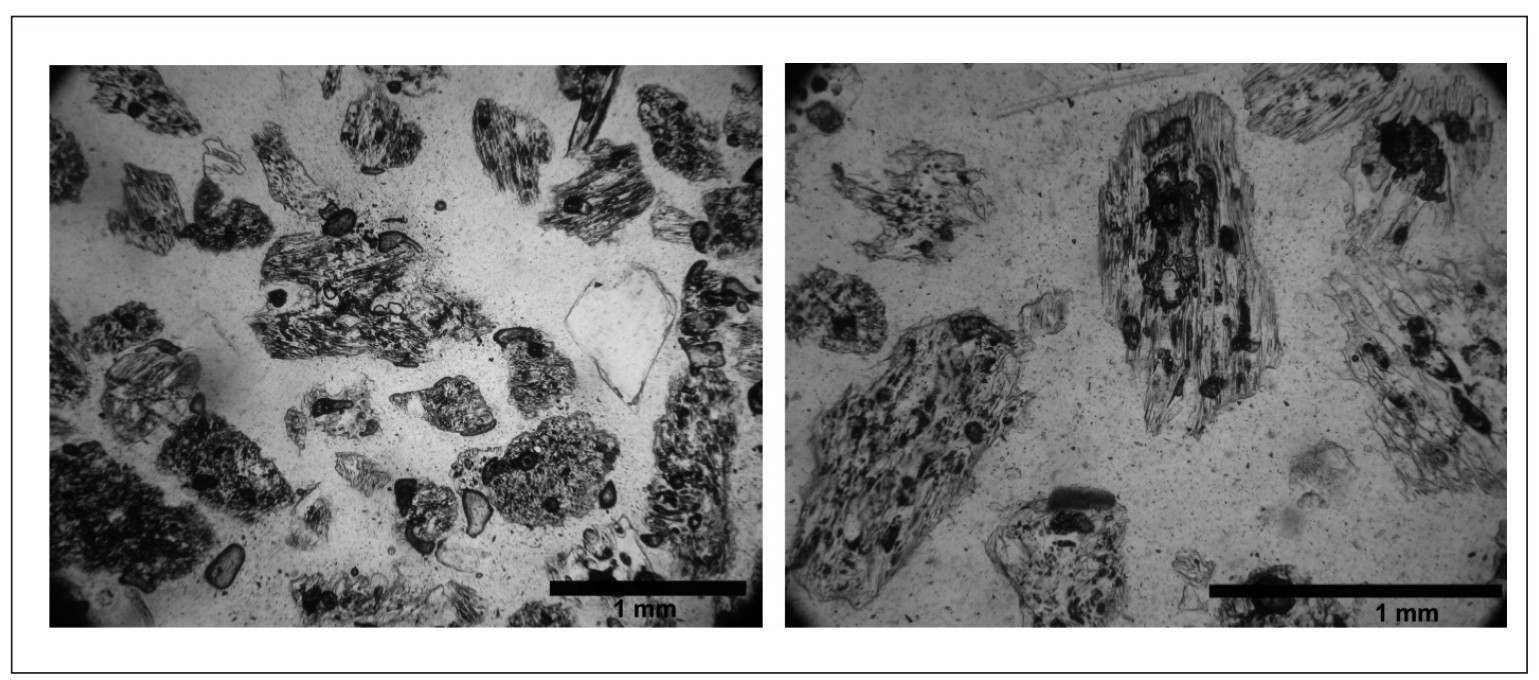

Figura 9. Fotomicrografías del sedimento 1. Tomadas a distintas escalas y sin polarizador.

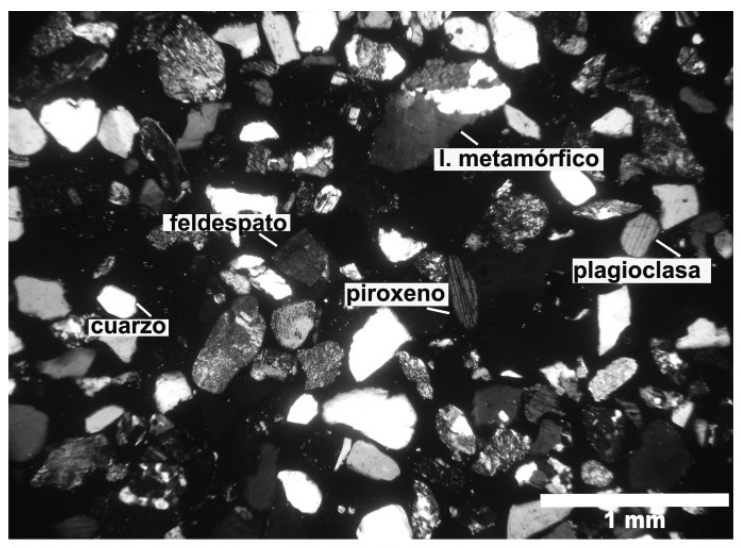

Fotomicrografía con polarizador

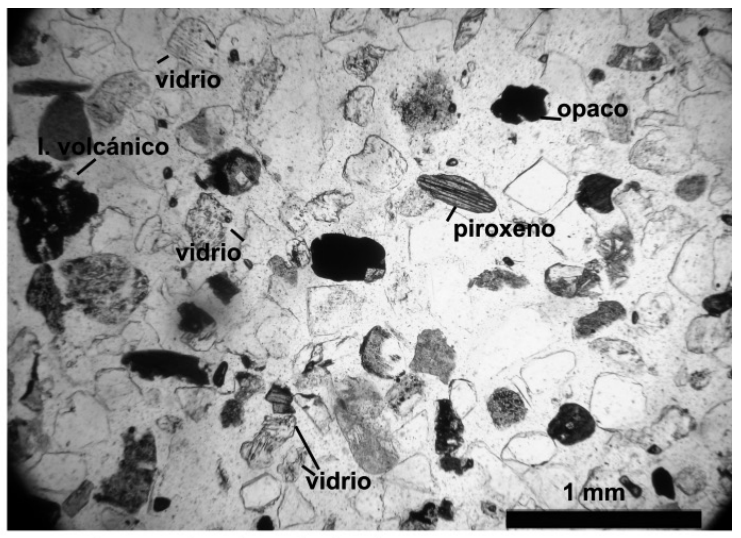

Fotomicrografía sin polarizador

Figura 10. Fotomicrografías del sedimento que acarrea el río El Bolsón. 


\section{Comparación petrográfica entre sedimentos y cerámica}

Las arenas del valle integran una gran diversidad litológica identificada también en la cerámica. Es por ello que en base la comparación petrográfica de ambos materiales - sedimentos y cerámica- planteo que la manufactura de las piezas analizadas fue realizada con materias primas disponibles localmente.

Como ha sido explicado en párrafos anteriores, en la cerámica aquí estudiada predominan las inclusiones no plásticas de cuarzo monocristalino, vidrio vesicular, líticos volcánicos, plagioclasa y feldespato potásico. En menor medida, se observa biotita, líticos graníticos, minerales opacos, líticos metamórficos y anfíboles. Esta combinación de minerales, material piroclástico y rocas de orígenes litológicos diferentes se encuentra presente en el sedimento que acarrea el río El Bolsón (sedimento 2). A su vez, es importante destacar que los clastos y trizas de vidrio vesicular que conforman el sedimento 1 poseen las mismas características que los clastos piroclásticos que acarrea el río y que están presentes en la cerámica. De este modo, ambas fuentes de antiplástico pueden haber sido utilizadas, tal vez en combinación, para elaborar gran parte de las piezas. Igualmente, considero que por sus características de tamaño y porcentaje de representación, la arena S.2 habría sido incorporada intencionalmente como temperante en los ejemplares donde está presente casi de manera exclusiva, como es el caso del ejemplar que compone el cluster $\mathrm{E}$, así como también de otros casos estudiados con lupa binocular donde este tipo de temperante se identifica como inclusiones blanquecinas (Puente 2010a, 2010b; Porto López y Puente 2011 Ms).

\section{* Discusión y conclusiones: modos de HACER PARTICULARES Y CÓDIGOS SOCIALES COMPARTIDOS}

Los objetos representan procesos de elaboración y transformación conformados por creencias y significaciones tanto para quienes los elaboran cómo para quienes los perciben y manipulan (Gell 1992). En palabras de Dobres (1999: 128), la tecnología es un tejido constituido por la interrelación de habilidades, conocimientos, valores, metas, necesidades funcionales, actitudes, tradicio- nes, relaciones de poder, constreñimientos materiales y productos finales, junto con la agencia, el artificio y las relaciones sociales del artesano. En este sentido, las prácticas de producción implican procesos, elecciones, relaciones y representaciones sociales situadas (Lemonnier 1993; Dobres y Hoffman 1999; Ingold 1999). Es por ello que considero que una manera adecuada de abordar el estudio de las prácticas de producción alfarera del pasado es a partir de un análisis que contemple de manera interrelacionada las características estéticas generales de las piezas terminadas (forma, color, diseños plásticos, tratamientos de superficie) y aquellos atributos o variables que nos permiten conocer tanto las materias primas utilizadas como inferir en parte el modo en que la pieza fue elaborada, aspecto que en este trabajo en particular se indagó a través de las pastas cerámicas (Falabella et al. 2002; Puente 2011a). Este abordaje holístico hacia los objetos cerámicos permite conocer un número importante de elecciones realizadas por los alfareros en el proceso de elaboración y, de este modo, identificar modos de hacer particulares como así también conjunto de elecciones compartidas por distintos artesanos.

Como ha sido desarrollado a lo largo del trabajo, el estudio petrográfico de las pastas cerámicas permite inferir, a partir de un número de variables, algunas de las elecciones que el alfarero realizó a lo largo del proceso de elaboración. Así, la naturaleza de las inclusiones no plásticas y su comparación con los sedimentos locales es una vía adecuada para conocer parte de las materias primas seleccionadas por el artesano, como así también establecer inferencias preliminares sobre su producción local o alóctona, resultados que necesariamente deben ser complementados con análisis químicos. Por otra parte, las características de densidad, porosidad, estructura del fondo de pasta y tamaño, forma y grado de selección de las inclusiones se encuentran vinculadas con las etapas de tratamiento y procesado de las materias primas, preparación de la pasta y cocción (Sheppard 1957; Rye 1981; Rice 1987).

Los resultados obtenidos en este trabajo evidencian gran homogeneidad en las materias primas utilizadas para la manufactura de las piezas reconocidas como de estilo Belén en el valle del Bolsón, donde específicamente predominan inclusiones no plásticas de vidrio vesicular y cuarzo entre otros clastos líticos y minerales. Asimismo, los análisis de AANI realizados en otra instancia de in- 
vestigación evidencian que estas piezas poseen un perfil químico multielemental similar, el que a su vez coincide con distintas fuentes de arcillas muestreadas en la región, por lo que se considera que la producción fue local (Puente 2011b). En este sentido, se aprecian elecciones compartidas por los distintos alfareros sobre las materias primas seleccionas para la manufactura de este conjunto y que se diferencian claramente de las utilizadas en la cerámica ordinaria recuperada en los mismos asentamientos (Puente 2011b, 2011c). Asimismo, se reconoce la coexistencia de modos de hacer particulares materializados en el resto de las variables petrográficas estudiadas: densidad, tamaño, forma y grado de selección de las inclusiones, porosidad y estructura del fondo de pasta. Al respecto, es significativo señalar que la diversidad en estas características atraviesa la variabilidad morfológica y de tratamiento de superficie registrada para el conjunto, es decir, no se distingue un patrón determinado de elaboración de las pastas para cada tipo de pieza. Esta variabilidad junto con la diversidad de modos de manufacturar vasijas de tamaño y forma similar identificadas en marcas técnicas presentes en distintos sectores de las piezas (Puente 2011a), manifiestan la ausencia de un único estándar de manufactura para las distintas variedades morfológicas recuperadas en la región.

En el mismo sentido cabe destacar que, en ejemplares enteros pertenecientes a la colección Schreiter que he estudiado junto con la Dra. Quiroga (Quiroga y Puente 2007a; Puente y Quiroga 2007b), se distinguen calidades diferentes en la terminación de las piezas. Hay vasijas que recibieron una terminación más "cuidada" que otras, evidenciado por ejemplo en el tratamiento de superficie empleado y en la presencia o no de marcas dejadas por la herramienta utilizada para su aplicación. Asimismo, en la incorporación de las asas y en los sectores de unión de los distintos segmentos de las vasijas, como pueden ser el cuello y el cuerpo o, el cuerpo y la base, en muchos casos se destacan y resaltan en la superficie externa las marcas de elaboración. Incluso varios ejemplares de la Forma 1 y 3 de la colección Schreiter están inclinados, posiblemente como consecuencia de que la vasija cedió por su propio peso dado que no se le dio el tiempo de secado necesario entre la elaboración de cada segmento.

De este modo, esta variabilidad en los modos de hacer -reconocida tanto en material fragmentario como en piezas enteras de colección- refleja elecciones diferen- ciales por parte de los alfareros en algunas etapas de la cadena operativa, las cuales pueden ser el resultado de distintas habilidades en la manufactura, de diversidad en los contextos donde se desarrolló la producción, de la función primaria a la que estuvo originalmente destinado el objeto, entre otras muchas opciones. Así, las diferencias encontradas pueden ser el resultado de elecciones que formaron parte de saberes, habilidades o experiencias distintas pero que buscaron generar objetos con características estéticas generales semejantes.

La forma en que se percibe un objeto, los elementos que se consideran significativos de ser percibidos - sea el tamaño, el color, la textura, la forma, el peso, la materia prima, etc.- y la significación particular que ello genera es contingente, es decir, no está anclada en el objeto sino que se sitúa en un contexto social particular (Gell 1998; Alberti 2001; Saunders 2001). Más allá de los elementos que se escapan a nuestro análisis, como dice Jones a través de identificación de similitudes y diferencias en los aspectos materiales y contextuales de los objetos, es posible abordar el estudio de las relaciones sociales en las cuales participaron (Jones 2001). En el conjunto de piezas "Belén” aquí estudiadas, se reconoce a través de las pastas la existencia de variabilidad en los modos de hacer correspondientes a las distintas instancias de la manufactura que ellas representan. Sin embargo, hay elecciones que se reproducen de manera constante: en lo "visible" el aspecto general de cada tipo de forma, la estructura del diseño, los temas y los campos de representación seleccionados para plasmarlos, los colores (mas allá de las diversas tonalidades de rojo o negro que puedan apreciarse), y en lo "oculto" las materias primas seleccionadas. Estos elementos que hoy percibimos como constantes fueron claramente seleccionados para ser reproducidos por los distintos artesanos. Es en este sentido que planteo la existencia de códigos sociales compartidos entre ellos.

¿Cómo se relacionan estos resultados con la organización de la producción alfarera? La coexistencia de modos de hacer diferenciados refleja la ausencia de estandarización en las prácticas de elaboración de las piezas y se encuentra íntimamente vinculada con la forma en que la producción de estos objetos estuvo organizada. ${ }^{12}$ En

12 La estandarización, definida como la uniformidad en las características de una clase de objeto, es un concepto que ha sido 
los modelos de desarrollo planteados para el período Tardío o Desarrollos Regionales en el área valliserrana del NOA, se propone que la producción de la alfarería utilizada como soporte de representaciones plásticas de amplia distribución regional, como es el caso de la cerámica de estilo Belén, fue de carácter especializada y estandarizada (Núñez Regueiro 1974: 183; Tarragó 2000: 270, 287). Este planteo surge en estrecha relación con el tipo de organización sociopolítica propuesto para dicho período, la presencia de jefaturas o señoríos locales, donde se considera que la élite es la encargada de controlar la producción y distribución de los bienes de prestigio, rol originalmente adjudicado a esta clase de alfarería. De este modo, una manera de lograr dicho control es que la producción quede en manos de pocos alfareros especializados, posiblemente ubicados en talleres de producción destinados a ese fin (Brumfield y Earle 1987; Earle 1987, 1991, 1994; Kristiansen 1991; Peregrine 1991; Blanton et al. 1996; Goldstein 2000; Trubitt 2000).

Comúnmente, en arqueología este tema es abordado desde la evidencia indirecta de producción brindada por el análisis de las pastas cerámicas. Si bien es una cuestión discutida, hay cierto consenso en considerar la homogeneidad tecnológica de las pastas como el indicador del tipo de especialización artesanal que se desarrolla en una cantidad limitada de unidades de producción por alfareros que comparten patrones de elaboración repetitivos (Rice 1981; Sinopoli 1988; Costin y Hagstrum 1995). ${ }^{13}$ Específicamente, para el caso del Tardío en el área valliserrana del NOA, esta perspectiva fue considerada para inferir la existencia de producción especializada y estandarizada en

estrechamente ligado al de especialización artesanal (Rice 1987; Sinopoli 1988; Blackman et al. 1993; Costin y Hasgtrum 1995; Laguens y Juez 2001, entre otros). Se plantea que si la estandarización es alta, indica que la producción fue realizada por alfareros especializados que utilizaron un rango limitado de materias primas y técnicas de manufactura rutinarias, como puede darse en un contexto de producción en masa en grandes talleres o barrios de artesanos (Rice 1987). Por su parte, Sinopoli (1988) considera a la estandarización como reflejo de una producción centralizada o administrada. Los atributos sobre los que se ha medido esta variable son diversos: dimensión y morfología de las piezas, decoración, tecnología y composición de las pastas (Rice 1981; Blackman et al. 1993; Costin y Hagstrum 1995).

13 Para una propuesta alternativa sobre la relación entre estandarización en las pastas y la especialización artesanal ver Arnold 2000. el sitio Batungasta, ubicado en el Valle de Abaucán (De la Fuente 2007), y la producción especializada de cerámica Santamariana y Famabalasto Negro Grabado en el valle de Yocavil (Piñeiro 1996; Sjödin 1998; Palamarczuk y Manasiewicz 2001; Palamarczuk 2002, 2008).

Para el caso específico del Valle del Bolsón, esta clase de inferencias se ve oscurecida por la escala temporal amplia que representan los materiales, período en el cual la organización y la escala de producción de la cerámica Belén pueden haber variado. Igualmente, los resultados alcanzados permiten generar hipótesis que serán evaluadas a medida que se obtenga una mayor resolución en la escala temporal de análisis. Concretamente, considero que la variabilidad de modos de hacer señalada evidencia la ausencia de un control estricto hacia la manufactura de estos ejemplares, como el que podría esperarse en el caso de una producción en manos de alfareros dedicados intensivamente a la elaboración de alfarería y cuyo objetivo fuera lograr piezas de formas, tamaños y/o pastas estandarizadas. En este sentido, planteo que la cerámica Belén del valle del Bolsón es el resultado de la coexistencia de distintas unidades de producción, posiblemente de pequeña escala y de baja intensidad productiva como la que puede esperarse en una producción de carácter doméstico. Como señalan Tarragó y Nastri, las narrativas que se formulan con las periodificaciones reducen la complejidad de los procesos sociales para poder facilitar la síntesis histórica, pero lo más valioso de estas formulaciones "...tiene que ver con las iluminaciones que puede(n) producir respecto del conocimiento de las particularidades propias de cada contexto" (Tarragó y Nastri 1999: 259). En este sentido, los resultados aquí alcanzados se alejan de la propuesta tradicional que teoriza el modelo y generan un aporte desde una base empírica específica para discutir la variabilidad de organizaciones de producción que pueden haberse desarrollado durante el tardío prehispánico en el área valliserrana del NOA.

La decisión compartida por los distintos alfareros sobre las materias primas a utilizar en la manufactura de la cerámica Belén materializa la existencia de códigos sociales compartidos entre los artesanos que van más allá de la escala o el contexto en que se desarrolló la producción. Esta elección compartida entre los alfareros se reproduce incluso a escalas regionales más amplias. Por ejemplo, en los conjuntos de alfarería Belén procedentes del valle del Hualfín los estudios petrográficos revelan importantes semejanzas con 
las muestras aquí analizadas y los investigadores que trabajan en dicha región también destacan la homogeneidad mineralógica del antiplástico y la diferencian de otros conjuntos cerámicos mayoritarios coexistentes en los mismos asentamientos (Wynveldt et al. 2005-07; Wynveldt 2008; Wynveldt y Iucci 2009; Zagorodny et al. 2010).

En síntesis, los códigos sociales compartidos entre los artesanos se expresan tanto en las características estéticas aquí mencionadas que poseen los ejemplares como en las materias primas que se consideraron adecuadas para elaborarlos. La homogeneidad en estos aspectos atraviesa la variabilidad en los modos de hacer relacionados con otras elecciones realizadas en la cadena de elaboración. De este modo, el análisis interrelacionado de los atributos que observamos en la pieza terminada y aquellos que nos informan sobre el modo en que fue elaborada revela la coexistencia de decisiones compartidas y otras diferenciadas en la manufactura, evidencia que cobra sentido dentro de una escala de análisis microsocial, es decir, en relación con las prácticas cotidianas donde los individuos o grupos sociales pequeños elaboran y usan sus objetos en un contexto sociohistórico particular. Por último, cabe destacar que dado que el estudio de estas prácticas es necesario para entender los procesos sociales acaecidos a escalas más amplias (Dobres y Hoffman 1994, 1999; Dobres 1999; Gosselain 2008), los resultados aquí obtenidos adquieren jerarquía en un doble sentido: en primer lugar porque se generó información hasta el momento desconocida sobre la producción alfarera a escala local; $y$, en segundo, éstos conocimientos contribuyen a la discusión sobre la diversidad de prácticas de producción que coexistieron durante el período Tardío Prehispánico en el área valliserrana del NOA.

Agradecimientos Deseo a agradecer a Teresita Montenegro y Pablo Leal, docentes de las cátedras de Mineralogía y Petrografía de la carrera de Cs. Geológicas de la UBA, por su asesoramiento en los análisis petrográficos. También va mi profundo agradecimiento a Lucas Pereyra Domingorena por el préstamo del microscopio y a Laura Quiroga por la lectura crítica del artículo. Este trabajo fue financiado con los siguientes subsidios: PIP - CONICET 5906, UBACYT - F 423 y PIP - CONICET 112-200801-00285.

\section{* Referencias citadas}

ADAMS, A. E., W. S. MACKENZIE y C. GUILFORD, 1997. Atlas de rocas sedimentarias. Masson, Barcelona.

ALBERTI, B., 2001. Faience goddesses and ivory bull-leapers: the aesthetics of sexual difference at Late Bronze Age Knossos. World Archaeology 33 (2): 189-205.

ARNOLD, D. E., 2000. Does the standardization of ceramic pastes really mean specialization? Journal of Archaeological Method and Theory 7 (4): 333-375.

ASCHERO, C. A., y M. A. KORSTANJE, 1993. About human figures, production and symbols. Some aspects of Northwestern Argentine Rock Art. En Valcamonica Symposium '93, pp. 1-15. Centro Camuno di Studi Preistorici, Capo di Ponte, Italia.

BARRACLOUGH, A., 1992. Quaternary sediment analysis: a deductive approach at A-level. Teaching Geography 17: 15-18.

BASILE, M., 2005. Iconografía funeraria Belén; aportes para la definición de un estilo decorativo. Tesis de licenciatura, Facultad de Filosofía y Letras, Universidad de Buenos Aires, Buenos Aires.
2009. Recorriendo trazos. Un aporte a la definición del estilo decorativo Belén. Arqueología 15: 13-40.

BENNETT, W. C., E. F. BLEILER y F. H. SOMMER, 1948. Northwest argentine archaeology. Yale University Publications in Anthropology 38, New Haven.

BLACKMAN M. J., G. J. STEIN y P. B. VANDIVER, 1993. The standardization hypothesis and ceramic mass production: technological, compositional, and metric indexes of craft specialization at Tell Leilan, Syria.American Antiquity 58 (1): 60-80.

BLANTON, R. E., G. M. FEINMAN, S. A. KOWALEWSKI y P. N. PEREGRINE, 1996. A dual-processual theory for the evolution of mesoamerican civilization. Current Anthropology 37 (1): 1-14.

BREGANTE, O., 1926. Ensayo de clasificación de la cerámica del noroeste argentino. Estrada, Buenos Aires.

BRUCH, C., 1911. Exploraciones arqueológicas en las provincias de Tucumán y Catamarca. Revista del Museo de La Plata XIX, primera parte (segunda serie, VI). 
BRUMFIELD, E., y T. EARLE, 1987. Specialization, exchange, and complex societies: an introduction, En Specialization, exchange and complex societies, E. Brumfield y T. Earle (Eds.), pp. 1-9. University Press, Cambridge.

CHILTON, E. S., 1999. One Size Fits All: Typology and Alternatives for Ceramic Research. En Material Meanings, E. S. Chilton (Ed.), pp. 44-60. The University of Utah Press, Utah.

CIGLIANO, E. M., 1958. Arqueología de la zona de Famabalasto. Departamento de Santa María (provincia de Catamarca). Revista del Museo de La Plata (Nueva Serie), 24: 29-122.

COSTIN, C. L., y M. B. HAGSTRUM, 1995. Standarization, labor investment, skill, and the organization of ceramic production in latte prehispanic highland Peru. American Antiquity 60 (4): 619-639.

COURTOIS, L., 1976. Examen au Microscope Petrographique des Ceramiques Archeologiques. Centre de Recherches Archeologiques. Notes et Monographies Techniques 8, Centre National de la Recherche Scientifique, Paris.

CREMONTE, M. B., 1996. Investigaciones arqueológicas en la Quebrada de la Ciénaga (Dpto. Tafí, Tucumán). Tesis de Doctorado. Facultad de Ciencias Naturales y Museo, San Salvador de Jujuy.

2004. Caracterización petrográfica de una muestra de pastas Aguada. Variaciones de manufactura y tipológicas. Chungará 36: 697-709.

CREMONTE, B., A. RAMÍREZ y S. M. PERALTA, 2007. Identificación y caracterización de manufacturas cerámicas no locales del pukará de Volcán. Petrografía de pastas y Fluorescencia de Rayos. En Cerámicas arqueológicas. Perspectivas arqueométricas para su análisis e interpretación, M. B. Cremonte y N. Ratto (Eds.), pp. 49-72. Universidad Nacional de Jujuy, Jujuy.

CRISCI, J. V., y M.F. LÓPEZ ARMENGOL, 1983. Introducción a la teoría y práctica de la taxonomía numérica. Secretaría General de la Organización de los Estados Americanos, Programa Regional de Desarrollo Científico y Tecnológico, Washington.

DE LA FUente, G. A., 2007. Producción y tecnología cerámica en Batungasta: estandarización, especialización y procedencia. (Valle de Abaucán, Dpto. Tinogasta, Pcia. de Catamarca, Argentina). Tesis de Doctorado en Ciencias Naturales, Universidad Nacional de La Plata, La Plata.

DIETLER, M., y I. HERBICH, 1998. Habitus, techniques, style: an integrated approach to the social understanding of material culture and boundaries. En The archaeology of social boundaries, M. Stark (Ed.), pp. 232-263. Smithsonian Institution Press, Washington y Londres.
DOBRES, M. A., 1999. Technology's links and chains: the processual unfolding of technique and technician. En The dynamics of technology, practice, politics and world views, M. A. Dobres y C. Hoffman (Eds.), pp. 124-146. Smithsonian Institution Press, Washington y Londres.

DOBRES, M. A., y C. HOFFMAN, 1994. Social agency and dynamics of prehistoric technology. Journal of Archaeological Method and Theory 1 (3): 211-258.

1999. The dynamics of technology, practice, politics and world views. Smithsonian institution press, Washington y Londres.

DRUC, I. C., y Q. H. GWYN, 1998. From clay to pots: a petrographical análisis of ceramic production in the Callejón de Huaylas, North-Central Andes, Perú. Journal of Archaeological Science 25: 707-718.

EARLE, T., 1987. Specialization and the production of wealth: Hawaiian chiefdoms and the Inka empire. En Specialization, exchange and complex societies, E. Brumfield y T. Earle (Eds.), pp. 165-188. Cambridge University Press, Cambridge.

1991. The evolution of chiefdoms. En Chiefdoms: Power, Economy and Ideology, T. Earle (Ed.), pp. 1-15. Cambridge University Press, Cambridge.

1994. Wealth finance in the Inka empire: evidence from the Calchaquí Valley, Argentina. American Antiquity 59: 443-460.

FALABELLA, F., L. SANHUEZA y E. FONSECA, 2002. Las materias primas de la cerámica Aconcagua Salmón y sus implicancias para la interpretación de la organización de la producción alfarera. Chungara 34 (2): 167-189.

FEELY, A., 2010. Estilos tecnológicos y tradiciones cerámicas del Bolsón de Fiambalá (Dpto. Tinogasta, Catamarca). Tesis de doctorado, Universidad de Buenos Aires, Buenos Aires.

FREESTONE, I., 1991. Extending ceramic petrology. En Recent Developments in Ceramic Petrology, A. Middleton y I. Freestone (Eds.), pp. 399-410. The British Museum, Londres.

GELL, A., 1992. The technology of enchantment and the enchantment of technology. En Anthropology art and aesthetics, J. Coote y A. Shelton (Eds.), pp. 40-63. Clarendon press, Oxford.

1998. Art and agency: an anthropological theory. Clarendon Press, Oxford.

GOLDSTEIN, P. S., 2000. Exotic goods and everyday chiefs: longdistance exchange and indigeneous sociopolitical development in the South Central Andes. Latin American Antiquity 11 (4):335-361. 
GONZÁLEZ, A. R., 1955. Contextos culturales y cronología relativa en el área central del N.O. argentino. Anales de Arqueología y Etnología XI: 7-32. Facultad de Filosofía y Letras, Universidad de Cuyo, Mendoza.

1963. Desarrollo cultural en el Noroeste Argentino. En Aboriginal cultural development in Latin American: an interpretative review, vol. 146 (1), B. Meggers y C. Evans (Eds.), pp. 103-107. Smithsonian Miscellanecus Collections, Washington.

GONZÁLEZ BONORINO, F., 1950. Geología y petrografía de las hojas $12 d$ (Capillitas) y 13d (Andalgalá). Ministerio de Industria y Comercio de la Nación, Buenos Aires.

GOODBY, R., 1998. Technological Patterning and Social Boundaries: Ceramic Variability in Southern New England, A.D. 10001675. En The Archaeology of Social Boundaries, M. Stark (Ed.), pp. 161-182. Smithsonian Institution Press, Washington y Londres.

GOSDEN, C., 2001. Making sense: archaeology and aesthetics. World Archaeology 33 (2): 163-167.

GOSSELAIN, O. P., 1998. Social and Technical Identity in a Clay Crystal Ball. En Social boundaries on the Sepik Coast of New Guinea, M. Stark (Ed.), pp. 78-106. Smithsonian Institution Press, Washington y Londres.

2008. Mother Bella Was Not a Bella. En Cultural transmission and material culture. Breaking down boundaries, M. Stark, B. J. Bowser y L.Horne (Eds.), pp. 150-177. The University of Arisona Press, Tucson.

INGOLD, T., 1999. Foreword. En The dynamics of technology, Practice, politics and world views, M. Dobres y C. Hoffman (Eds.), pp. viixii. Smithsonian Institution Press, Washington y Londes.

JONES, A., 2001. Drawn from memory: the archaeology of aesthetics and the aesthetics of archaeology in Earlier Bronze Age Britain and the present. World Archaeology 33 (2):334-356.

KERR, P. F., 1965. Mineralogía óptica. McGraw-Hill Book Company, New York.

KORSTANJE, M. A., 2005. La organización del trabajo en torno a la producción de alimentos en sociedades agropastoriles formativas (Provincia de Catamarca, República Argentina). Tesis de doctorado, Instituto de Arqueología y Museo, Facultad de Cs. Naturales e Instituto Miguel Lillo, Universidad Nacional de Tucumán, Tucumán.

2007. Territorios campesinos: producción, circulación y consumo en los valles altos. En Producción y circulación prehispánicas de bienes en el sur andino, A. E. Nielsen, M. C. Rivolta, V. Seldes,
M. M. Vázquez y P. H. Mercolli (Eds.), pp. 191-224. Colección Historia Social Precolombina 1, Editorial Brujas, Córdoba.

KORSTANJE, M. A., y C. A. ASCHERO, 1996. Sobre figuraciones humanas, producción y símbolos. Aspectos del Arte Rupestre del Noroeste Argentino. En Volumen del XXVAniversario del Museo Arqueológico "Dr. Eduardo Casanova", pp. 1-19. Instituto Interdisciplinario Tilcara, Jujuy.

KORSTANJE, M. A., y A. E. WURSCHMIDT, 1999. Producir y recolectar en los valles altos del NOA: "Los Viscos" como caso de estudio. En En los tres reinos: prácticas de recolección en el Cono Sur de América, C. A. Aschero, M. A. Korstanje y P. M. Vuoto (Eds.), pp. 151-160. Instituto de Arqueología y Museo, Facultad de Cs. Naturales e Instituto Miguel Lillo, Universidad Nacional de Tucumán, Tucumán.

KRISTIANSEN, K., 1991. Chiefdom, states, and systems of social evolution. En Chiefdoms: power, economy and ideology, T. Earle (Ed.), pp. 16-43. Cambridge University Press, Cambridge.

LAFONE QUEVEDO, S. A., 1892. Catálogo descriptivo e ilustrado de las Huacas de Chañar Yaco. Revista del Museo de La Plata 3: 33-63.

LAGUENS, A., y M. S. JUEZ, 2001. Especialización en la manufactura cerámica de pucos Aguada. Actas del XIII Congreso Nacional de Arqueología Argentina, tomo II: 489-504. Córdoba.

LEMONNIER, P., 1992. Elements for an anthropology of technology. Museum of Anthropology, Michigan.

1993. Introduction. En Technological choices: Transformation in material cultures since the Neolithic, P. Lemonnier (Ed.), pp. 1-35. Routledge, Londres.

MAHIAS, M. C., 2002. Pottery techniques in India. Technical variants and social choice. En Technological choices. Transformation in material cultures since the Neolithic, P. Lemonnier (Ed.), pp. 157180. Routledge, Londres.

MIDDLETON, A., y I. FREESTONE, 1991. Recent developments in ceramic petrology. Ocasional Paper num. 81, The British Museum, London.

NÚÑEZ REGUEIRO, V., 1974. Conceptos instrumentales y marco teórico en relación al análisis del desarrollo cultural del Noroeste Argentino. Revista del Instituto de Antropología 5: 169-190.

ORTON, C., P. TYERS y A. VINCE, 1997. La Cerámica en Arqueología. Crítica, Barcelona.

OUTES, F., 1907. Alfarerías del Noroeste Argentino. Anales del Museo de La Plata, I (segunda serie): 5-49. 
PÁEZ, M. C., B. MANASSE y G. TOSELLI, 2007. Alfarería Tardía con inclusiones blancas en el Valle de Tafí, Provincia de Tucumán. Aportes Científicos desde Humanidades 7: 270-282.

PALAMARCZUK, V., 2002. Análisis cerámicos de sitios del bajo de Rincón Chico Valle de Yocavil, Provincia de Catamarca. Tesis de licenciatura en Ciencias Antropológicas, Universidad de Buenos Aires, Buenos Aires.

2008. Un análisis de la cerámica arqueológica de cuatro sitios en el bajo de Rincón Chico. En Estudios arqueológicos en Yocavil, M. N. Tarragó y L. R. González (Eds.), pp. 19-80. Asociación de Amigos del Museo Etnográfico, Buenos Aires.

PALAMARCZUK, V., y M. MANASIEWICZ, 2001. "Tiempos antiguos": centralización y estandarización en la producción de la cerámica Famabalasto Negro Grabado. Libro de Resúmenes del XIV Congreso Nacional de Arqueología Argentina, pp. 193. Universidad Nacional de Rosario, Rosario.

PEREGRINE, P., 1991. Some political aspects of craft specialization. World Archaeology 23: 1-11.

PEREYRA DOMINGORENA, L., 2010. Manufacturas alfareras de las sociedades aldeanas del primer milenio DC al sur de los valles calchaquies. Tesis de doctorado, Universidad de Buenos Aires, Buenos Aires.

PIÑEIRO, M., 1996. Manejo de recursos y organización de la producción cerámica en Rincón Chico, Catamarca. Relaciones de la Sociedad Argentina de Antropología XXI: 161-185.

PORTO LÓPEZ, J. M., y V. PUENTE, 2011 Ms. Análisis composicional de alfarería con inclusiones de origen piroclástico. Conjuntos procedentes del Valle del Bolsón (Belén, Catamarca), ca. 900-1600 DC. Ponencia presentada en el IV Congreso Argentino de Arqueometría. Universidad Nacional de Luján. Manuscrito en poder de la autora.

PUENTE, V., 2008 Ms. Caracterización tecnológica y composicional de alfarería Belén. Un abordaje desde la petrografía cerámica. Ponencia presentada en las Jornadas sobre avances en técnicas analíticas aplicadas al estudio de materiales en arte y arqueología. Facultad de Ingeniería, Universidad de Buenos Aires, Buenos Aires. Manuscrito en poder de la autora

2010a. Análisis petrográfico de conjuntos cerámicos Tardíos: un aporte a la identificación de estilos tecnológicos en el Valle del Bolsón (Belén, Catamarca). En La Arqueometría en Argentina y Latinoamérica, pp. 91-96. Editorial de la Facultad de Filosofía y Humanidades, Universidad Nacional de Córdoba, Córdoba.

2010b. Manufactura cerámica, producción y reproducción de identidades sociales. Una discusión a partir de conjuntos cerámicos Tardíos del Valle del Bolsón (Belén, Catamarca). En Arqueología Argentina en el Bicentenario de la Revolución de Mayo, J. R. Bárcena y H. Chiavazza (Eds.), pp. 193-198. Facultad de Filosofía y Letras UNCuyo, Mendoza.

2011a. Abordando el estudio de las prácticas alfareras desde material arqueológico fragmentario. En La cerámica arqueológica en la materialización de la sociedad. Transformaciones, metáforas y reproducción social, M. C. Páez y G. De La Fuente (Eds.), pp. 9-26. BAR - British Archaeological Report 14, Southamerican Archaeological Series, Londres.

2011b. Prácticas de producción alfarera en el Valle del Bolsón (Belén, Catamarca): materias primas y modos de hacerca. 900-1600 DC. Tesis de doctorado, Universidad de Buenos Aires, Buenos Aires.

2011c. Prácticas de producción alfarera durante el tardío prehispánico en el valle del Bolsón. Un aporte desde la tecnología cerámica del sitio El Duraznito (Belén, Catamarca, Argentina). Arqueología 18. En prensa.

PUENTE, V., y L. QUIROGA, 2007a. El tratamiento plástico de la figura humana en las urnas de Belén. Elementos para su interpretación. Memorias del III Congreso de Historia de Catamarca, tomo I: $237-245$.

2007b. Percepción de la forma, variabilidad del conjunto estilístico Belén (colección Schreiter). Mundo de antes 5: 157-184.

QUIROGA, L., 2002. Paisaje y relaciones coloniales en el Valle de Cotahau. Del tardío a la ocupación colonial. Tesis de doctorado, Universidad de Sevilla, Sevilla.

2003. Belén: Debates en torno a la construcción de un objeto de estudio. Runa 24: 151-171.

2004a Ms. Chacra y potrero, paisaje y relaciones sociales en el oeste catamarqueño. Ponencia presentada en el XIX Congreso de Historia Económica. San Martín de los Andes, Neuquén. Manuscrito en poder de la autora.

2004b. Arquitectura residencial en La Angostura (Valle del Bolsón, Belén, Catamarca). Resúmenes del XV Congreso Nacional de Arqueología Argentina: 74-75. Universidad Nacional de Río Cuarto, Córdoba.

2007a. Arquitectura de la vivienda prehispánica y colonial. Una perspectiva comparativa en el área valliserrana del Noroeste Argentino. Actas del Congreso Internacional de Arquitectura Vernácula: 71-77.

2007b Ms. La experiencia del espacio construido: relevamiento y representación gráfica de arquitectura y entorno 
Lo QUe “oculta" el estilo: MATerias primas y modos De haCer en la Alfarería Belén...

(Punta de la Peña 3 Antofagasta de la Sierra - La Angostura El Bolsón - Catamarca). Ponencia presentada en el II Congreso Nacional y I Latinoamericano de Arqueometría. Universidad de San Martín, Centro Atómico Constituyentes, Buenos Aires. Manuscrito en poder de la autora.

2009a. Al Abrigo de sus Huaycos, espacios de refugio, espacios de reproducción. TANOA II. UNJu, San Salvador de Jujuy. En prensa.

2009b Ms. Perderse en la tierra por caminos extraviados, las tierras altas en la guerra de calchaquí. Ponencia presentada en las XII Jornadas Interescuelas. Bariloche. Manuscrito en poder de la autora.

2010a. En sus huaycos y quebradas: Formas materiales de la resistencia en las tierras de Malfin. Memoria Americana 18 (2): 185-209.

QUIROGA, L., y M. A. KORSTANJE, 2005. Arqueología del campesinado en el valle del Bolsón. Producción y residencia como líneas de análisis para una escala de larga duración. En Uso de sistemas de información geográfica en la arqueología sudamericana, M. J. Figuerero Torres y A. D. Izeta (Eds.). BAR, Oxford. En prensa.

QUIROGA, L., y V. PUENTE, 2007a. Imagen y percepción: iconografía de las urnas Belén. Colección Schreiter. En Procesos sociales prehispánicos en el sur andino. La vivienda, la comunidad y el territorio, A. E. Nielsen, M. C. Rivolta, V. Seldes, M. M. Vázquez y P. H. Mercolli (Eds.), pp. 323-346. Colección Historia Social Precolombina 1. Editorial Brujas, Córdoba.

2007b Ms. Lenguajes plásticos diferenciados: Un acercamiento a la variabilidad estilística del tardío en el área de Hualfín y El Bolsón. XVI Congreso Nacional de Arqueología Argentina. San Salvador de Jujuy, Jujuy, Argentina. Manuscrito en poder de la autora.

RICE, P., 1981. Evolution of specialized pottery production: A trial model. Current Anthropology 22 (3): 219-240.

1987. Pottery analysis, a sourcebook. The University of Chicago Press, Chicago y Londres.

RYE, O., 1981. Pottery technology. Principles and reconstruction. Manuals on Archaeology 4. Taraxacum Inc., Washington.

SANHUEZA, L., 2004. Estilos tecnológicos e identidades sociales durante el período alfarero temprano en Chile Central: una mirada desde la alfarería. Tesis de magíster, Facultad de Antropología y Ciencias sociales, Universidad de Santiago, Santiago.
SAUNDERS, N. J., 2001. A dark light: reflections on obsidian in Mesoamerica. World Archaeology 33 (2): 220-236.

SEMPÉ, M. C., 1977. Las culturas agroalfareras prehispánicas del valle de Abaucán (Tinogasta, Catamarca). Relaciones de la Sociedad Argentina de Antropología 9: 55-68.

SERRANO, A., 1966. Manual de la cerámica indígena. Segunda edición. Assandri, Córdoba.

SHENNAN, S., 1992. Arqueología cuantitativa. Crítica, Barcelona.

SHEPPARD, A., 1957. Ceramics for the archaeologist. Carnegie Institution of Washington, Washington.

SINOPOLI, C., 1988. The organization of craft production at Vijayanagara, South India. American Anthropologist 90 (3): 580597.

SJÖDIN, S., 1998. Clay pots and the potters work. Archaeology and ethno-archaeology at Pichao in North-werstern Argentina. Etnologiska Studier 42. Past and present in Andean Prehistory and Early History, pp. 33-52. Goteborg, Sweden.

STARK, M., 1999. Social dimensions of technical choice in Kalinga ceramic traditions. En Material meanings, E. S. Chilton (Ed.), pp. 24-43. The University of Utah Press, Utah.

STARK, M., M. ELSON y J. CLARK, 1998. Social Boundaries and Technical Choices in Tonto Basin Prehistory. En The Archaeology of Social Boundaries, M. Stark (Ed.), pp. 208-231. Smithsonian Institution Press, Washington y Londres.

STOLTMAN, J. B., 2001. The rol of petrography in the study of archaeological ceramics. En Earth sciences and archaeology, P. Goldberg, V. T. Holliday y C. Reid Ferring (Eds.), pp. 297-326. Kluwer Academic/ Plenum Publishers, New York.

TARRAGÓ, M., 200o. Chacras y pukará. Desarrollos sociales tardíos. En Nueva historia argentina, pp. 257-301. Editorial Sudamericana, Buenos Aires.

TARRAGÓ, M., yJ. NASTRI, 1999. Dimensiones de la complejidad Santamariana. Actas XII Congreso Nacional de Arqueología Argentina, tomo II: 259-264.

TRUBITT, M. B., 200o. Mound building and prestige goods exchange: changing strategies in the Cahokia chiefdom. American Antiquity 65 (4): 669-690.

TURNER, J. C., 1973. Descripción geológica de la hoja 11d, Laguna Blanca Provincia de Catamarca. Ministerio de Industria y Minería, Buenos Aires. 
VAN DER LEEUW, S., 2002. Giving the potter a choice. Conceptual aspects of pottery techniques. En Technical choices. Transformation in material cultures since the neolithic, P. Lemonnier (Ed.), pp. 238-288. Routledge, Londres y Nueva York.

WYNVELDT, F., 2006. Funcionalidad y cronología en un sitio del período de Desarrollos Regionales (Loma de los Antiguos, Depto. de Belén, Catamarca). Tesis de doctorado, Universidad Nacional de La Plata, La Plata.

2007. La estructura del diseño decorativo en la cerámica Belén (Noroeste Argentino). Boletín del Museo Chileno de Arte Precolombino 12 (2): 47-67.

2008. Tecnología cerámica Belén: caracterización macroscópica y conceptualización en la manufactura alfarera. Intersecciones en Antropología 9: 157-172.
2009. La Loma de los Antiguos de Azampay. Un sitio defensivo del valle de Hualfin (Catamarca, Argentina). Sociedad Argentina de Antropología, Buenos Aires.

WYNVELDT, F., N. ZAGORODNY y M. MOROSI, 2005-07. Tendencias morfométricas y caracterización composicional de la cerámica Belén en el Valle de Hualfín (Belén, Catamarca). Actas del I Congreso Argentino de Arqueometría, pp. 95-106. Rosario.

WYNVELDT, F., y M. E. IUCCI, 2009. La cerámica Belén y su definición a través de la historia de la arqueología del NOA. Relaciones, Sociedad Argentina de Antropología, XXXIV: 275-296.

ZAGORODNY, N., M. MOROSI, M. E. IUCCI y F. WYNVELD, 2010. Estudios composicionales de las pastas de la cerámica tardía de distintos sitios del Valle de Hualfín (Belén, Catamarca). Arqueología 16. En prensa. 